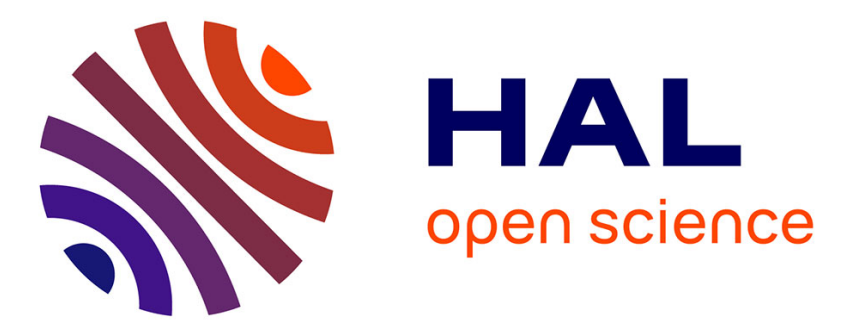

\title{
Dynamic single-cell phenotyping of immune cells using the microfluidic platform DropMap
}

Yacine Bounab, Klaus Eyer, Sophie Dixneuf, Magda Rybczynska, Cécile

Chauvel, Maxime Mistretta, Trang Tran, Nathan Aymerich, Guilhem Chenon, Jean-François Llitjos, et al.

\section{To cite this version:}

Yacine Bounab, Klaus Eyer, Sophie Dixneuf, Magda Rybczynska, Cécile Chauvel, et al.. Dynamic single-cell phenotyping of immune cells using the microfluidic platform DropMap. Nature Protocols, 2020, 15 (9), pp.2920-2955. 10.1038/s41596-020-0354-0 . hal-03054278

\section{HAL Id: hal-03054278 https://hal.science/hal-03054278}

Submitted on 31 Dec 2020

HAL is a multi-disciplinary open access archive for the deposit and dissemination of scientific research documents, whether they are published or not. The documents may come from teaching and research institutions in France or abroad, or from public or private research centers.
L'archive ouverte pluridisciplinaire HAL, est destinée au dépôt et à la diffusion de documents scientifiques de niveau recherche, publiés ou non, émanant des établissements d'enseignement et de recherche français ou étrangers, des laboratoires publics ou privés. 


\section{FILE NOT INTENDED FOR PRODUCTION}

\section{Dynamic Single-Cell Phenotyping of Immune Cells using the Microfluidic 3 Platform DropMap}

4

5 Yacine Bounab ${ }^{1,2 \S}$, Klaus Eyer ${ }^{3,45}$, Sophie Dixneuf ${ }^{1}$, Magda Rybczynska ${ }^{3,}$ Cécile Chauvel $^{1}$, Maxime Mistretta ${ }^{1}$

6 ,Trang $\operatorname{Tran}^{1}$, Nathan Aymerich ${ }^{3}$, Guilhem Chenon ${ }^{3}$, Jean-François Llitjos ${ }^{5}$, Fabienne Venet ${ }^{6,7}$, Guillaume

7 Monneret $^{6,7}$, lain Gillespie ${ }^{8}$, Pierre Cortez ${ }^{9}$, Virginie Moucadel ${ }^{6,10}$, Alexandre Pachot ${ }^{10}$, Alain Troesch $^{1}$, Philippe

8 Leissner $^{1}$, Julien Textoris ${ }^{6,10,11}$, Jérôme Bibette ${ }^{3}$, Cyril Guyard ${ }^{1}$, Jean Baudry ${ }^{3 *}$, Andrew D. Griffiths ${ }^{2 *}$ and

9 Christophe Védrine ${ }^{1 *}$.

$10{ }^{1}$ BIOASTER Technology Research Institute, Lyon, France.

11 'Laboratoire de Biochimie (LBC), École Supérieure de Physique et de Chimie Industrielles de la Ville de Paris 12 (ESPCI Paris), Université Paris Sciences et Lettres (PSL), CNRS UMR8231, Paris, France.

${ }^{3}$ Laboratoire de Colloïdes et Matériaux Divisés (LCMD), École Supérieure de Physique et de Chimie Industrielles de la Ville de Paris (ESPCI Paris), Université Paris Sciences et Lettres (PSL), CNRS UMR8231, Paris, France.

${ }^{4}$ Laboratory for Functional Immune Repertoire Analysis, Institute of Pharmaceutical Sciences, D-CHAB, ETH Zürich, Zürich.

${ }^{5}$ Medical intensive care unit of Cochin hospital, Paris, France.

${ }^{6}$ EA7426 “Pathophysiology of Injury-induced immunosuppression”, Université Claude Bernard Lyon-1 - HCLbioMérieux, Lyon, France.

${ }^{7}$ Immunology Laboratory, Hospices Civils de Lyon, Lyon, France.

${ }^{8}$ GlaxoSmithKline, Brentford, Middlesex, UK.

${ }^{9}$ R\&D, Sanofi Aventis, Chilly-Mazarin, France.

${ }^{10}$ Medical Diagnostic Discovery Department (MD3), bioMérieux S.A., France.

${ }^{11}$ Anesthesiology and Critical Care Medicine, HCL, Lyon, France.

${ }^{\S}$ These authors contributed equally 
Dr Christophe Védrine, BIOASTER Technology Research Institute, Bâtiment François Jacob, 28, rue du Docteur Roux, 75015 Paris, France. Email: christophe.vedrine@bioaster.org.

Pr Andrew D Griffiths, Laboratoire de Biochimie (LBC), ESPCI Paris, PSL Université, CNRS UMR8231, Paris,

Dr Jean Baudry, Laboratoire de Colloïdes et Matériaux Divisés (LCMD), ESPCI Paris, PSL Université, CNRS UMR8231, Paris, France. Email: jean.baudry@espci.fr

EDITORIAL SUMMARY This protocol describes a microfluidic platform for dynamic high-throughput analysis the phenotype of single cells. Cell-surface markers and secreted proteins are quantified and characterized by fluorescence detection using tailored immunoassays, simultaneously with measurement of other cellular characteristics, including endocytosis activity and viability.

TWEET A new protocol describes a microfluidics-based assay for high-throughput interrogation of protein secretion kinetics in single cells. @BIOASTER @EyerFira @ETH_DCHAB

42

COVER TEASER Microfluidics-based analysis of protein secretion

Up to three primary research articles where the protocol has been used and/or developed.

1. Eyer, K., Doineau, R. C. L., Castrillon, C. E., Briseño-Roa, L., Menrath, V., Mottet, G., et al. (2017). Single-cell deep phenotyping of IgG-secreting cells for high-resolution immune monitoring. Nature Biotechnology, 35(10), 977-982. http://doi.org/10.1038/nbt.3964 
51 Characterization of immune responses is currently hampered by the lack of systems allowing quantitative and dynamic phenotypic characterization of individual cells, and especially analysis of secreted proteins such as cytokines and antibodies. We recently developed a simple and robust microfluidic platform, DropMap, to measure simultaneously the kinetics of secretion and other cellular characteristics, including endocytosis activity, viability and expression of cell-surface markers, from tens of thousands of single immune cells. Single cells are compartmentalized in $50 \mathrm{pL}$ droplets and analyzed using fluorescence microscopy combined with an immunoassay based on fluorescence relocation to paramagnetic nanoparticles aligned to form beadlines in a magnetic field. The protocol typically takes 8-10 hours after preparations of microfluidic chips and chambers, which can be prepared in advance. In contrast, enzyme-linked immunospot (ELISPOT), flow cytometry, time of flight mass cytometry (СуTOF), and single-cell sequencing only allow end-point measurements, and do not allow direct, quantitative measurement of secreted proteins. We illustrate how this system can be used to profile downregulation of tumor necrosis factor- $\alpha$ (TNF- $\alpha$ ) secretion by single monocytes in septic shock patients, and to study immune responses by measuring rates of cytokine secretion from single $T$ cells and to measure affinity of antibodies secreted by single B cells. 
The last few years have seen rapid progress of single-cell sequencing technologies in both fundamental and clinical research ${ }^{1-3}$. Single-cell RNA sequencing (scRNA-seq), in particular, is proving to be a powerful tool to study gene expression at the single-cell level and to characterize cell-type diversity ${ }^{4}$. Although methods such as droplet-based scRNA-seq ${ }^{5}$ enable high-throughput analysis of tens-of-thousands of individual cells, measuring transcriptional profiles is not sufficient to fully understand cellular activity, as protein concentration and subcellular localization cannot be reliably inferred from mRNA expression levels ${ }^{6,7}$. As proteins are implicated in most biological functions, numerous approaches have been developed to assess protein expression at the single-cell level. In particular, fluorescence-based flow cytometry ${ }^{8}$ and time of flight mass cytometry $\left(\right.$ CyTOF) ${ }^{9}$, which allow medium to high-throughput single-cell phenotyping based on the detection of intracellular and cell-surface proteins, but not secreted proteins. The inability to directly detect secreted proteins can be partially alleviated using experimental strategies such as blockage of secretion pathways ${ }^{10,11}$, but it is neither possible to tell whether the protein is secreted or stored intracellularly, nor to measure secretion rates. Fluorescence microscopy and flow cytometry allow reliable simultaneous analysis of 6-10 distinct markers, while CyTOF allows simultaneous detection of as many as 40 markers ${ }^{9,12,13}$. Recently, droplet-based single-cell sequencing techniques have also been developed to quantify cellsurface proteins using antibodies labeled with oligonucleotides ${ }^{7,14,15}$ (rather than fluorescence or mass tags), which allows simultaneous analysis of the transcriptome of the same cell ${ }^{7,14}$. In contrast, enzyme-linked immunospot (ELISPOT) ${ }^{16}$ has been used extensively to detect proteins secreted from individual cells. Although simple to implement, this technique is poorly quantitative. ELISPOT assays can be used to determine the frequency of secreting cells but, even then, discrimination between signals due to secretion and background staining can be difficult ${ }^{17,18}$. Importantly, ELISPOT, flow cytometry, CyTOF, and single-cell sequencing are all only based on end-point measurements, which do not reflect the dynamic nature of cellular behavior.

There is, hence, a need for quantitative high-throughput systems that allow dynamic single-cell phenotyping, including detection of secretion rates and binding activities of both cell-surface and secreted proteins. This information is crucial for the accurate analysis of immune responses that are mediated by both cell-membrane receptors and secretion of soluble factors, notably antibodies, chemokines and cytokines $^{19}$. Deciphering dynamic processes at the single-cell level is critical to describe and understand the fundamental mechanisms underlying immunity, to develop new and improved strategies for vaccination and cancer immunotherapy, and to diagnose and treat inflammatory, autoimmune and infectious diseases. 
Recently, novel technologies, based on microfabrication and microfluidics, have been developed to analyze the secretome of individual cells ${ }^{20-31}$, some of which have been used to measure the secretion of multiple cytokines and to detect antibody secretion and antigen binding ${ }^{30,31}$. Compartmentalization of individual cells in picoliter volume droplets in microfluidic systems ${ }^{32,33}$ has also been used for high-throughput screening and sorting of antibody-secreting cells based on the binding or inhibitory activity of secreted antibodies ${ }^{34-36}$ and to analyze cellular heterogeneity in cytokine-secreting immune cells ${ }^{37}$. Although promising, these assays are only based on endpoint data and do not reflect the dynamic expression of immune response.

To overcome these limitations, we have recently described a simple and robust droplet microfluidic method, DropMap (Fig. 1), which we used to study the humoral immune response in mice immunized with tetanus toxoid ${ }^{38}$. With DropMap, single IgG-secreting cells are compartmentalized in tens of thousands of $50 \mathrm{pL}$ droplets to form a stationary two-dimensional droplet array allowing kinetic analysis by optical microscopy. A fast and ultrasensitive in-droplet immunoassay, based on fluorescence relocation to paramagnetic nanoparticles that are aligned to form beadlines in a magnetic field, allows simultaneous measurement of the IgG secretion rate and affinity for thousands of single cells in parallel. In our study, we discovered that immunization results in dramatic increases in the range of both single-cell secretion rates and IgG affinities, which spanned at maximum 3 and 4 logs, respectively ${ }^{38}$. We also showed differences in dynamics of secretion rates and affinities of IgGs within and between spleen and bone marrow ${ }^{38}$.

Here we present a detailed step-by-step protocol for the DropMap system, and describe how the system can be extended to study a range of different immune cells, including B cells, $T$ cells and monocytes, and to analyze the secretion of a variety of different proteins, such as different antibody isotypes, and a variety of murine and human cytokines (including TNF- $\alpha$, IFN- $\gamma$; IL-2 and IL-6). We also describe how the measurement of secretion can be combined with the measurement of other parameters, including affinities of secreted antibodies, expression of cell-surface markers, endocytosis and cell viability. The method is rapid and sensitive, enabling, for example, the detection of secreted proteins from a single cells in as little as $30 \mathrm{~min}$, compared to generally more than 6 hours for conventional single-cell assays such as ELISPOT ${ }^{16}$. It is a flexible system to analyze humoral, cellular and innate immune responses. To illustrate the performance of DropMap, we describe its applications to immune responses analyses in a murine immunization model by measuring secretion rate and affinity of antibodies secreted by single B cells. Importantly, from a clinical standpoint, we also reveal the downregulation profiles of TNF- $\alpha$ secretion by single monocytes obtained from septic shock patients. 
137 ELISPOT, flow cytometry, CyTOF, and scRNA-seq are all based on endpoint measurements, which is 138 advantageous for throughput but does not reflect the dynamic nature of cellular behavior. They do not allow the quantitative characterization of secreted proteins by living cells. Recently, commercially available technologies based on compartmentalizing cells in microfabricated chambers have been developed to perform a range of assays, including real-time IgG and cytokine secretion, apoptosis and cell-cell interaction ${ }^{39-41}$. For example, the Berkeley Lights system allows optofluidic handling and analysis of single cells, including recovery of individual cells for sequence analysis, but can analyze $\sim 10,000$ cells as the system currently has 14115 chambers ("nanopens"), whereas the DropMap system can currently analyze up to 300,000 cells. Furthermore, when used to analyze antibody secretion, the Berkeley Lights system only provide a binary (yes/no) result ${ }^{41}$, whereas, DropMap enable simultaneous determination of both antibody secretion rate and affinity. Other technologies using droplet microfluidics have been developed for high-throughput, single-cell, protein secretion measurement $35,37,42,43$. However, as previously mentioned, these are endpoint approaches, and do not assess the dynamic nature of single-cell secretome. Droplet microfluidics has also been used for real-time measurement of T cell activation upon recognition of target tumor cells Segaliny et al. However, the number of droplets containing $T$ cells and target cancer cells was low (due to Poisson statistics of cell encapsulation) ${ }^{44}$. DropMap, in contrast, allows the direct measurement of protein secretion by individual living cells and the quantitative assessment of secreted proteins. Hence, using DropMap, the dynamic behavior of single-cells can be measured over time, allowing, for example, the direct and quantitative assessment of secretion rates of proteins such as antibodies, cytokines and chemokines, and, in the case of antibodies, DropMap enables simultaneous determination of both antibody secretion rate and affinity. A DropMap chamber surface of $1 \mathrm{~cm}^{2}$ allows the observation and analysis of 60,000 droplets: i.e. around 20,000 cells over up to 12 hours. Currently, the maximum number of cells we have detected simultaneously with DropMap is around 300,000 cells with a time resolution around 21 minutes. The number of eukaryotic cells that can be analyzed is therefore similar to the number that can be analyzed by scRNA-seq $\left(\sim 10^{5}\right)$, ELISPOT $\left(\sim 10^{5}\right.$ per well) and using microfabricated nanowells $\left(\sim 10^{5}\right)$, but less than can be analyzed using flow cytometry $\left(\sim 10^{8}\right)$ CyTOF $\left(\sim 10^{7}\right)$ or droplet microfluidics with in-flow detection, where, using a similar magnetic beadline-based immunoassay, as many as 2.5 million eukaryotic cells can be analyzed per experiment ${ }^{45}$. The maximum number of markers that can currently be detected simultaneously with DropMap is 4, as described herein, but it should be possible to extend this to 6-10 markers, as for the other systems based on epifluorescence microscopy. The use, in DropMap, of an assay based on fluorescence relocation also negates the need for washing within the protocol. 
173 Our protocol inherits the generic limitations of closed homogenous fluorescence-based assays. Once

174 immobilized, nothing can be added or extracted from the droplets without losing their identity (as 175 defined by their position). Therefore, the immunoassay cannot be washed, no enzymes can be used 176 for signal amplification, and multi-step assays are not possible. The immunoassays sensitivity and 177 range is defined by the number of added nanoparticles and detection reagent, therefore care should 178 be taken when adapting the sensitivity and range of the assay to prevent excess false-positive or 179 negative results (see also Box 1 and 2).

180 The biggest drawback of the protocol is the need for a known analyte of interest, since in the sandwich immunoassays the antibody pair is chosen according to the analyte, and the performance of the assay depends critically on the affinity and specificity of the antibodies. Also, when assaying secreted antibodies, since purified antigens are used in the assays, cross-reactivities or unspecific offtarget binding of the antibodies are not taken into account and need to be characterized using other methods.

Due to the need for imaging in different fluorescent channels, care should be taken regarding optical phenomena such as pixel saturation, photo-bleaching or spectral overlap. This overlap also limits the number of readouts that could be used to probe several cellular functions within the droplets, thus reducing the multiplexing capability when compared to CYTOF or single-cell sequencing. Long-term studies over days are also limited due to the inability to add fresh nutrients to the cells without losing their identity. Therefore, the longest experimental time is defined by the disappearance of a crucial nutrient, or the accumulation of waste products in the droplets. This depends on the nature of the cells analyzed, but using mammalian cells (Chinese hamster ovary, $\mathrm{CHO}$ cells), the longest assay we have performed is 12 hours. The frequency of dead cells (stained with propidium iodine) encapsulated in droplets was not significantly different from the reference culture in a standard $\mathrm{CO}_{2}$ incubator over 12 hours of incubation time $(3.2 \pm 1.6 \%$ and $2.6 \pm 1.6 \%$, for droplets and the reference culture respectively. $\mathrm{N}=3$, two-tailed unpaired t test $\mathrm{p}=0.67$ ).

A competent graduate student or post-doc can perform the protocol. There are two crucial parts of the protocol. First, the extraction and preparation of the biological sample, i.e. the cells, is of great importance. These should be extracted and prepared with the least stress possible since even minor 
The work with human and animal samples needs to be performed by properly trained and skilled experimenters, with appropriate safety precautions, with ethical approval where necessary, and in accordance with local legislation. Second, the proper preparation of the chamber and droplets is of high importance to eliminate or restrict droplet movement over time and improve data quality and reliability of the process, but a researcher from any discipline easily masters the procedure.

\section{Experimental design}

The DropMap protocol is based on compartmentalizing single cells in tens of thousands of $50 \mathrm{pL}$ droplets that are immobilized in two-dimensional droplet arrays and analysed by fluorescence microscopy ${ }^{38}$ (Fig.1). The droplets can be therefore monitored over time and cellular dynamics are captured by taking images at regular intervals. Compartmentalization of single cells in droplets allows the measurement of secreted molecules which remain in the droplets, in combination with measurements of cell-surface markers and other phenotypic characteristics. Secreted molecules are quantified using a fluorescence relocation-based, sandwich immunoassay. The analytes are captured on antibody-coated paramagnetic nanoparticles in the droplets using a capture antibody. These nanoparticles are aligned to form a beadline by applying a magnetic field, and the captured analytes are quantified by measuring relocation of a fluorescently-labelled detection antibody to the beadline. The protocol consists of six major stages:

Microfabrication of the droplet production chip (Steps 1-22). Microfluidic chips for droplet production are fabricated in poly(dimethysiloxane) (PDMS) using soft-lithography ${ }^{46}$ as described previously ${ }^{35}$. Droplet-makers are also commercially available from a variety of commercial suppliers for laboratories without the necessary equipment and facilities to perform these steps. The droplet production chip is designed to produce monodisperse $50 \mathrm{pL}$ droplets using hydrodynamic flow focusing ${ }^{47}$ and contains three inlets to introduce, respectively, (i) the fluorinated carrier oil containing fluorosurfactant, (ii) the suspension of cells and (iii) the assay reagents (functionalized nanobeads, labelled detection probes, a live/dead cell probe, and others), as well as one outlet for collecting the produced droplets $^{35}$ (Fig. 1 and see Supplementary Data 1 for the complete chip design - CAD file).

Microfabrication of the droplet incubation chamber (Steps 23-30). The immobilization and storage of aqueous droplets in a 2D array is the core of the DropMap approach. Immobilization of the droplets allows for time-course measurements of droplet-based biological assays ${ }^{48-53}$. Due to the height of the chamber being less than the droplet diameter, the observation chamber is able to immobilize $50 \mathrm{pL}$ droplets. Incubations and observations over time are therefore made possible for short to medium time ranges ( $5 \mathrm{~min}$ to $<24 \mathrm{~h}$ ) at temperatures between $4^{\circ} \mathrm{C}$ and $37^{\circ} \mathrm{C}$. 
237 We use a simple, cost-effective and reproducible method based on double-sided tape and two 238 standard microscope slides $(75 \mathrm{~mm} \times 25 \mathrm{~mm} \times 1 \mathrm{~mm}$ ) to fabricate the droplet incubation device (Fig. 239 2, see Supplementary Data 2 and 3 for the mask for the double-sided tape to prepare the 240 observation chamber and the mask for laser ablation). The fabrication method is flexible and 241 customized microfluidic chambers can be fabricated depending on the droplet volume and the 242 number of droplets to be analyzed: several double-sided adhesive tapes with different thicknesses 243 are commercially available (for example from $3 \mathrm{M}$ ) and any observation chamber shape and size can 244 be made by cutting the tape using a plotter. The use of glass results in an optically transparent 245 system, whilst the double-sided tapes used adheres strongly and stably to the glass surfaces 246 preventing fluid leakage and evaporation. Lastly, after the experiments the chamber can be cleaned 247 and reused several times. To do so, the outer surfaces are cleaned with ethanol or isopropanol and 248 the chamber flushed with pure fluorinated oil to remove droplets.

249 Functionalization of nanoparticles (Steps 31A-31B). Another important key feature of our dropletbased immunoassay is the use of many paramagnetic nanoparticles per droplet (see also Box 3). Magnetic nanoparticles are well-suited to immunodetection technologies owing to their large surface-to-volume ratio, monodispersity, stability and easy manipulation in a magnetic field. Compared to approaches relying on the co-encapsulation of a single cell and a single microparticle ${ }^{35}$, the use of nanoparticles increases the binding capacity and lowers the number of droplets containing no particles, which improved the performance of the assay. The protocol was optimized so that, once a strong magnetic field is applied, each droplet contains a single, homogeneous, elongated aggregate of hundreds of nanoparticles, which appears in the bright-field images as a horizontal dark beadline located in the droplet (Fig. 1,3). The number of nanoparticles per droplet defines the capacity of the immunoassay, and can be adjusted to the expected secretion rates to allow optimal results. However, a certain minimum (100-200 beads/droplet) is needed to form a measurable beadline.

261 Secreted molecules are captured onto paramagnetic nanoparticles for detection, typically via capture 262 antibodies. The immobilization of capture antibodies onto the nanoparticles is a crucial step for the 263 success of the protocol ${ }^{54-59}$. The performance of antibody-based biosensors is directly related to the 264 orientation of antibodies on the nanoparticles and accessibility of the paratope that binds the 265 targeted analyte. In this protocol, we describe the use of two targeted coupling strategies. First, we 266 describe a boronic acid (BA)-based coupling strategy for precise orientation of capture antibodies on the surface of magnetic nanoparticles ${ }^{54,60-62}$ (Fig. 3a-C) and second, a strategy based on biotinylated capture antibodies coupled to streptavidin-coated nanoparticles (Fig. 3d-f). 
Automated image acquisition (Steps 38-45). To perform imaging, the microfluidic chamber is placed on a motorized stage of an inverted epifluorescence microscope. In our case, 10X magnification was used as a compromise between scanning time and resolution for object detection within each droplet. We image between 75-225 fields of view in multiple channels (up to five, depending on the integrated assays): 75 fields of view $\left(135 \mathrm{~mm}^{2}\right)$ results in around 60,000 imaged droplets; i.e. 1020,000 cells. Throughput can be improved by increasing the imaged area. However, when scanning large areas of a sample with high resolution, scanning time as well as processing time (of large amount of imaging data) can become limiting steps for the throughput of the procedure. Here, binning of pixels during acquisition may help to solve some of these issues.

As both automated object detection and fluorescence intensity measurements rely on focus quality, control of focus drift throughout the imaging procedure (of a large area over long times) is crucial. Mechanical effects, vibrations, thermal changes and droplets movement can cause the focus to drift. We addressed this limitation by using the Perfect Focus System (PFS) of the Nikon microscope, but other microscopes might offer similar solutions.

Cell preparation, encapsulation and incubation in droplets (Steps 46A-46B). This analytical system is suitable for many different cells from various tissues and species. Primary cells are sensitive and fragile, therefore requiring gentle handling during extraction and manipulation. Due to the quantitative nature of the measurements described in this protocol, even small deviations might result in significant differences. Gentle handling and rapid extraction of cells is important, and for optimal results, the cells should be present as a singularized suspension. Before encapsulation, the cell density needs to be adjusted so that the frequency of droplets containing a single cell is maximized, while minimizing the frequency of droplets containing multiple cells (see Box 3 ) $^{35}$.

Compartmentalization of cells in droplets will further affect cell survival. The surfactant is a key reagent for the droplet assays ${ }^{35,63}$ : it must be non-cytotoxic, and must stabilize droplet interfaces and prevent the coalescence of droplets during incubation. The use of the nonionic perfluoro-polyether fluorosurfactant $(600 \mathrm{~g} / \mathrm{mol} \text { PEPE tails and } 2000 \mathrm{~g} / \mathrm{mol} \text { heads })^{35}$ in combination with fluorinated carrier oils such as HFE-7500 (3M) is recommended. At some point, nutrient depletion and $\mathrm{pH}$ changes will be a limiting factor for long-term studies of the encapsulated cells. The in-droplet pH is maintained by the addition of $\mathrm{HEPES}^{64}$, and the fluorinated oil, which can dissolve $~ 20$ times more oxygen than water ${ }^{65}$, used as a continuous phase, additionally serves as an, albeit limited, oxygen reservoir $^{66,67}$. In addition, as fluorinated oils are very poor solvents for non-fluorinated molecule ${ }^{68,69}$ they are well suited for cell-based and biochemical assays. Various biocompatible fluorinated oils and 
fluorosurfactants can be ordered from a large number of suppliers such as $3 \mathrm{M}$, RAN Biotechnologies, Dolomite, Sphere Fluidics and Bio-Rad. We confirmed the survival of primary monocytes over a 12hour time span, and the survival of primary murine splenocytes over the same time-period in $50 \mathrm{pL}$ droplets. Furthermore, we added in our protocol a simple and sensitive cytotoxicity assay to discriminate dead and live cells to exclude any signals that might stem from dead or dying cells.

Image processing (Steps 47A-47B). We developed a robust, custom-made Matlab-based software to detect and, if necessary, track droplets in time-lapse image sequences and monitor the status of their content over time. The software analyses the images over time in different fluorescence and bright field channels. First, the droplets are detected in bright field images using an algorithm that detects circles of a given diameter. In a next step, a binary mask of the detected droplets is generated, and this mask is overlaid onto the following fluorescence images to analyze each droplet separately. Within each droplet, the software measures the fluorescence of droplets, cells and beadlines (Fig. 4).

The software output is a spreadsheet containing morphological and fluorescence intensity parameters for different intra-droplet objects or regions over time. All measured fluorescence intensities on objects (i.e. magnetic beadline, cell or whole droplet) are normalized by the background fluorescence of the droplet in order to compensate locally for potential heterogeneity of illumination of the field, increase the sensitivity (signal-to-noise ratio is more differentiating than the raw beadline signal), and reduce the impact of photobleaching on results. 


\section{Biological materials}

- Human blood ! CAUTION Experiments using human blood samples must conform to the relevant Institutional and National regulations and requires informed consent from all participants. See just below for the permissions obtained for the use of human blood for this Protocol:

- Samples from septic shock patients (Table 1) were obtained from the prospective cohort MICROFLU-SEPSIS which has been approved by the French Ethical Committee CPP Sud Ouest et Outre Mer 4 (registration number 2017-A01134-49). Patients were included in the medical intensive care unit of Cochin hospital and informed consent was obtained from all the participants or their legally authorized representatives.

- $\quad$ For sepsis application, blood sample collection from healthy donors was performed according to the Ethical Committee of the Investigation Clinique et Acces aux Resources Biologiques (ICAReB) platform (Dr Marie-Noelle Ungeheuer, Centre de Recherche Translationnelle, Institut Pasteur, Paris, France) as part of the DIAGMICOLL or CoSImmGEn ( ${ }^{\circ}$ CORC: 2008-16 and 201-06) protocol, which has been approved by the French Ethical Committee (CPP), Ile-de-France. Informed consent was obtained from all donors (Table 1).

- $\quad$ For cytokine-secreting T-cells application, Peripheral Human blood was also collected from healthy patients at the "Etablissement Français du Sang". Donors were recruited after a medical selection process complying with French regulations, and they gave their informed consent to participation in the study.

- Mouse spleen and bone marrow. In this protocol, we used Mus musculus, BALB/cJRj, females, age 8-10 weeks at the start of the immunization, supplied by Janvier Laboratories. ! CAUTION Experiments using animal samples must conform to the relevant Institutional and National regulations. In this work, the mice experiments have been validated by the CETEA ethics committee number 89 (Institute Pasteur, Paris, France) under \#2013-0103, and by the French Ministery of Research under agreement \#00513.02, and were part of larger scientific study.

\begin{tabular}{|c|c|c|c|c|}
\cline { 2 - 5 } \multicolumn{1}{c|}{} & Gender & Age & Sepsis source & SOFA $^{\#}$ \\
\hline Septic Patient 1 & Male & 61 & Cutaneous & 8 \\
\hline Septic Patient 2 & Female & 88 & Urinary tract & 6 \\
\hline
\end{tabular}




\begin{tabular}{|c|c|c|c|c|}
\hline Septic Patient 3 & Female & 63 & Osteo-articular & 8 \\
\hline Healthy Donor 1 & Male & 47 & ND & ND \\
\hline Healthy Donor 2 & Female & 42 & ND & ND \\
\hline Healthy Donor 3 & Female & 35 & ND & ND \\
\hline
\end{tabular}

353

354

355

356

357

358

359

360

361

362

363

364

365

366

367

368

369

370

371

372

373

374

375

376

377

378

379

380

381

382

383

384

- Table 1. Characteristics of healthy donors and septic patients at admission in the intensive care unit. Gender, age, sepsis source and SOFA score. The SOFA (Sequential Organ Failure Assessment) score is a bedside applicable score designed to score organ dysfunction with less focus on mortality prediction.

\section{Reagents -}

CAUTION Wear appropriate protective clothing and equipment when manipulating chemical and biological reagents.

- Ultrapure DNase/RNase-free distilled water (Invitrogen, cat. no.10977049).

- Isopropanol (VWR 208224321). ! CAUTION Isopropanol liquid and vapor is highly flammable. Handle away from ignition sources and fire.

- Acetone (VWR 322201). ! CAUTION Acetone liquid and vapor is highly flammable. Handle away from ignition sources and fire.

- Ethanol (VWR 208224321). ! CAUTION Ethanol liquid and vapor is highly flammable. Handle away from ignition sources and fire.

- $1 \mathrm{H}, 1 \mathrm{H}, 2 \mathrm{H}, 2 \mathrm{H}$-Perfluorododecyltrichlorosilane (Sigma-Aldrich, cat. no. 729965)! CAUTION This reagent is corrosive and moisture sensitive. Work in a fume hood to avoid inhalation of silane.

- HFE-7500 (3M, cat. no. 98-0212-2928-5)! CAUTION Avoid direct contact with this liquid, as it may cause respiratory, skin and eye irritation.

- Fluorinated surfactant (Ran Biotechnologies, cat. no 008).

- Poly(dimethyl siloxane) (PDMS) and curing agent (Dow Corning, Sylgard 184).

\section{Application sepsis}

- Bovine Serum Albumin (BSA) (Sigma-Aldrich, cat. no A7960).

- Roswell Park Memorial Institute (RPMI) 1640 Medium (PanBiotech, cat. no. P04-17500).

- Phosphate Buffered Saline (PBS) (Dominique Dutscher, cat. no. L0612-500).

- Penicillin-streptomycin (Life Technologies, cat. no. 15140-122).

- HEPES (Dominique Dutscher, cat. no. L0180-100).

- Fetal Bovine Serum (FBS) (HyClone cat. no. SH30070.03).

- Anti-CD14, blue violet conjugate (Clone TÜK4) (Miltenyi Biotec Cat\# 130-094-364, RRID:AB 10831023), Lot\# 5171130409. 
400

401

402

403

404

405

406

407

408

409

410

411

412

413

414

415

416

417

418

419

420

421

422

423

424

- Capture anti-TNF- $\alpha$ antibody (Antibody TNF5) (MABTECH Cat\# 3510-6-1000, RRID:AB 907379), Lot\#16, non-biotinylated).

- Detection PE-anti-TNF- $\alpha$ antibody Clone: cA2 (Miltenyi Biotec Cat\# 130-120-489 without azide Cat\#120-014-229, RRID:AB 2752115), Lot\#5160222264.

- Recombinant TNF- $\alpha$ protein (Biolegend, cat. no. 570108).

- NucView488 (Biotium, cat. no. 99949).

- MitoView633 (Biotium, cat. no. 99950).

- LPS (Sigma-Aldrich, cat. no. L2637, 3012 and 3137).

- Dextran 20 \% (wt/wt), 500 kDa (Sigma-Aldrich, cat. no. D8802).

- $300 \mathrm{~nm}$ dimeter Carboxyl Adembeads (Ademtech, cat. no 2131).

- EDC (Thermo Fisher Scientific, cat. no. 77149). ! CRITICAL This material is moisture sensitive. Upon receipt, make aliquots and store them at $-20^{\circ} \mathrm{C}$.

- SulfoNHS (Thermo Fisher Scientific, cat. no 24510). ! CRITICAL This material is moisture sensitive. Upon receipt, store at $4^{\circ} \mathrm{C}$.

- Ethanolamine (Sigma-Aldrich, cat. no E9508). ! CAUTION This material is irritant. Work in a fume hood.

- $10 \times$ Activation buffer 10X for Carboxyl-Adembeads Coupling (Ademtech, cat. no 10101)

- $10 \times$ Storage Buffer 10X (Ademtech, cat. no 10201)

- 3-aminophenylboronic Acid (Sigma, cat. no A71751)

- EasySep Direct Human Monocyte isolation Kit (STEMCELL Technology, cat. no 19669).

\section{Application murine IgG-secreting cells}

- Knockout Serum Replacement (Thermo Fisher Scientific, cat. no. 1082808).

- Human Serum Albumin (rHSA), recombinant (SigmaAldrich, cat. no. A9731).

- HEPES (ThermoFisher, cat. no. 15630080).

- DPBS (ThermoFisher, cat. no. 14190250).

- Penicillin-streptomycin (Life Technologies, cat. no. 15140-122).

- Pluronic F-68, 10\% (wt/vol) sterile filtered solution (Thermo Fisher Scientific, cat. no. 24040032).

- Pluronic F-127, 10\% (wt/vol) sterile filtered solution (Thermo Fisher Scientific, cat. no. P6866).

- RPMI 1640 Medium without phenol red (ThermoFisher, cat. no. 11835030).

- $300 \mathrm{~nm}$ diameter Bio-Adembeads Strepatividin plus (Ademtech, cat. no. 03132).

- CaptureSelect ${ }^{\mathrm{TM}}$ Biotin Anti-LC-kappa (Murine) Conjugate (ThermoFisher Scientific, cat. no. 7103152100), Lot\#160707-02.

- AffiniPure $F\left(a b^{\prime}\right)_{2}$ Fragment Rabbit Anti-Mouse IgG, Fcy fragment specific (Jackson ImmunoResearch Labs Cat\# 315-606-047, RRID:AB 2340252), Lot\#103179.

- CellTrace ${ }^{\mathrm{TM}}$ Violet Cell Proliferation Kit (ThermoFisher Scientific, cat. no. C34557).

- Zenon ${ }^{\mathrm{TM}}$ Alexa Fluor ${ }^{\mathrm{TM}} 488$ Mouse IgG2b Labeling Kit (Thermo Fisher Scientific Cat\# Z25202, RRID:AB 2736943), Lot\#1450052. 
- IFN gamma Monoclonal Antibody (MD-1) (Thermo Fisher Scientific Cat\# 14-7317-85, RRID:AB 468474), Lot\#4295084, biotinylated in house.

- IFN gamma Monoclonal Antibody (clone 4S.B3), APC conjugate (Thermo Fisher Scientific Cat\# 17-7319-82, RRID:AB 469506), Lot\#4281150.

- TNF alpha Monoclonal Antibody (MAb1) (Thermo Fisher Scientific Cat\# 14-7348-85, RRID:AB 468488), Lot\#E05529-432, biotinylated in house.

- TNF alpha Monoclonal Antibody (MAb11), PE conjugate (Thermo Fisher Scientific Cat\# 127349-81, RRID:AB 466207), Lot\#4290466.

- IL-2 Polyclonal Antibody, Biotin (Thermo Fisher Scientific Cat\# 13-7028-81, RRID:AB 466900), Lot4307122 and 2049448.

- IL-2 rabbit anti-human (PeproTech Cat\# 500-P22-100ug, RRID:AB 147898), Lot\#0204CY12RB, labelled in house with Alexa 555

- IL-4 Monoclonal Antibody (MP4-25D2), Biotin conjugate (Thermo Fisher Scientific Cat\# 137048-81, RRID:AB 466904), Lot\#1963900.

- IL-4 Monoclonal Antibody (8D4-8), APC conjugate, (Thermo Fisher Scientific Cat\# 17-7049-81, RRID:AB 469497), Lot\#4275080.

- Anti-human CD3, clone HIT3a, Alexa Fluor ${ }^{\circledR} 647$ conjugate (BioLegend Cat\# 300322, RRID:AB 493693), Lot\#RT2101610.

\section{EQUIPMENT -}

\section{General lab equipment}

- Gloves (Crolex powder-free nitrile).

- Microscope slides, frosted ground-edges (VWR, cat. no. 63115553).

- Ultraviolet curing adhesive (Nurland optical adhesive, cat. no.68 P/N 6801).

- Disposable slide for cell counting: Fast Reader 102 (Dominique Dutscher, cat. no. 390498).

- Reusable biopsy punch diameter $0.75 \mathrm{~mm}$ and $6 \mathrm{~mm}$ (WPI, cat. no. 504529 and 504532).

- Sterican needles $23 \mathrm{G}$ for $0.56 \mathrm{~mm}$ diameter microtubing (Braun, cat no; 921021).

- Sterican needles $27 \mathrm{G}$ for 0.30mm diameter microtubing (Braun, cat no. 921018).

- PTFE microtubing (0.56 × 1.07 mm; Fisher Scientific, cat. no. 1192-9445).

- PTFE microtubing (0.30 × 0.76 mm; Fisher Scientific, cat. no. 1191-9445).

- $\quad$ Sterile $1 \mathrm{ml}$ syringes (Braun Omnifix, cat. no. 9204512).

- Sterile low binding microcentrifuge tubes (Dominique Dutscher, cat.no 27210).

- Petri dishes (100 mm diameter $\times 15$ mm; BD Falcon, cat. no. 351029).

- Nanoport 6-32 (Cil , cat no N-126-01).

- $\quad$ Cap (Cil, cat no P-555).

- MicroTight fittings (Cil, cat no P126S).

- Three low pressure syringe pumps neMESYS 290N, and control module Base 120 (both Cetoni).

- Vortex LMS (Dominique Dutscher, cat. no 079030). 
- Adjustable 2.5, 10, 20, 200 and 1,000 $\mu \mathrm{l}$ pipettes and sterile pipette tips (Eppendorf, cat no.: 3123000012; 3123000020; 3123000039; 3123000055; 3123000063).

- $2.5,10,20,200$ and 1,000 $\mu$ l sterile pipette tips ART (Thermo Fisher Scientific).

- Carousel holder for 6 micropipettes Research or 6 Multipettes (Dominique Dutscher, cat. no 33076).

- Smart Spatula (Dominique Dutscher, cat.no. 059362).

- Centrifuge (Eppendorf 5810R and 5418R).

- Magnet holder for 1.5 microtube (Ademtech, cat. no 20101).

- EasySep Magnet (STEMCELL Technology, cat.no. 180001). ! CAUTION Strong magnetic field. Handle it carefully and keep it away from objects that respond to magnetic field.

- Falcon ${ }^{\circledR}$ Round-Bottom Polystyrene Tubes, 5 and $15 \mathrm{~mL}$ (Dominique Dutscher, cat. no. 352051).

- Rapid-flow filter unit $0.2 \mu \mathrm{m}$-PES membrane 0.75 mm (Thermo Fisher Scientific, cat. no. 5660020).

- Sonicator: Bransonic Model B200 ultrasonic cleaner (Dominique Dutscher, cat. no. 910586).

- Mini shaker vortex Lab Dancer (Dominique Dutscher, cat. no 250097).

- Rotating shaker SB3 Stuart (Dominique Dutscher, cat. no 250097).

- Drum 40 microtubes $1.5 \mathrm{~mL}$ (Dominique Dutscher, cat. no 90435).

- Inverted microscope for droplet generation (Olympus IX83).

- 96-well microtiter microplate (Greiner, cat.no. 650185).

- 96-well dark microtiter plate (Corning, cat.no 3991).

- Magnet holder for 96-well plate (Ademtech, cat. no 20106).

- Plate reader infinite M200 Pro (TECAN).

\section{Chip fabrication}

- Disposable mixing cups (Dominique Dutscher, cat no 045108).

- Aluminum foil (Alupro, cat. no. A0626).

- Oven (Binder $300^{\circ} \mathrm{C}$, Dominique Dutscher cat. no. 9010-0190).

- Vacuum desiccator (Sigma-Aldrich, cat. no D2672).

- Scalpel (Becton Dickinson, No. 11, cat. no. 371611).

- Oxygen plasma cleaner (Femto Science, Inc. CUTE.MRP).

\section{Chamber fabrication}

- UV light source 5 (Opticure LED, Tech Optics Led, cat. no. 5090-200).

- Tweezers Dark blue forceps $111 \mathrm{~mm}$ (Dutscher, cat no. 037876).

- $\mathrm{CO}_{2}$ Laser (AxysLaser, $\mathrm{C} 180 \mathrm{ii}-\mathrm{CO} 2$ ), or alternative method for drilling $1 \mathrm{~mm}$ holes in glass.

- Graphtec Cutting plotter CE6000-40 (Graphtec) or CAMEO plotter (Silhouette).

\section{Chamber fabrication for sepsis application}


- Double-sided adhesive tape (Adhesive Research, cat. no. 92712).

- $\quad$ Binder clips (safe tool, cat no.: 8140.19; 8140.32).

- Magnet (FIRST4MAGNETS, cat. no. F75103). ! CAUTION These magnets are powerful. They can be dangerous, handle them carefully. Keep it away from objects that respond to magnetic field.

- Oven (Binder $300^{\circ} \mathrm{C}$, Dominique Dutscher cat. no. 9010-0190).

\section{Chamber fabrication for IgG application}

- Orafol Tape Series 1375 (Orafol, SDAG Adhésifs).

- Silicone paper ( $135 \mathrm{~g} / \mathrm{m}^{2}$, SDAG Adhésifs). ! NOTE The Orafol 1375 is only covered on one side with paper. Use this tape to cover the other side, and cut through this tape in the assembly to generate optimal results for chamber fabrication.

- 2 Magnets (K\&J Magnetics, cat. no. BZX082). ! CAUTION These magnets are powerful. They can be dangerous, handle them carefully. Keep it away from objects that respond to magnetic field.

- 3D printed holder for magnets (according to the Supplementary File 4)

- Thermopress capable of a pressing 7 bar and heating to $150^{\circ} \mathrm{C}$ (Scamex).

\section{Microscope and image acquisition}

- Inverted microscope for time-lapse imaging (Nikon, Eclipse Ti-2E):

- Digital CMOS camera (ORCA FLASH 4 LT, Hamamatsu); 2048(V) x 2048(H) pixel array with 6.5 x $6.5 \mu \mathrm{m}^{2}$ pixel size.

- Transmission light source (powerful white LED, pE-100wht, CoolLED). It replaces typical 100W halogen lamp.

- LED-based excitation light engine (Lumencor, SOLA SE II,).It replaces mercury arc lamp.

- 10x CFI Plan Apochromat Objective (Nikon, cat. no. MDR00105).

- Microscope enclosure and temperature controller (Oko-lab, cat. no. H201-T-UNIT-BL).

- Motorized $x y$ stage (Nikon, cat no MECS MEC56110).

- Software for stage control and image acquisition (Nikon, cat no NIS-AR Log MQS3 1000).

- Perfect Focusing System 2 (PFS2, Nikon, cat. no. MEP59390). ! CRITICAL: Needed to retain focus over large measurement areas.

- DAPI fluorescence cube (Nikon, cat. no. DAPI-5060C: Exc. 377/50 nm, Em. 447/60 nm, Cutoff $409 \mathrm{~nm})$

- GFP fluorescence cube (Nikon, cat. no. GFP-1828A: Exc. 482/18 nm, Em. 520/28 nm, Cutoff $495 \mathrm{~nm})$

- CY3 fluorescence cube (Nikon, cat. no. CY3-4040C: Exc. 531/40 nm, Em. 593/40 nm, Cutoff $562 \mathrm{~nm})$ 
- CY5 fluorescence cube (Nikon, cat. no. CY5-4040C: Exc. 628/40 nm, Em. 692/40 nm, Cutoff $660 \mathrm{~nm})$

\section{Software and analysis workstation}

- MATLAB (MathWorks, version 2018a, Image processing toolbox, VLFeat open source library, https://www.vlfeat.org/install-matlab.html).

- MATLAB Image analysis workstation: 8 Virtual processors, $2.6 \mathrm{GHz}, \mathrm{RAM} 64 \mathrm{~GB}$.

- DropCell.exe (https://doi.org/10.6084/m9.figshare.11336663.v1). CRITICAL Before first use of the Matlab application, it will have to be installed on your computer. This is done automatically by running the provided MyApplnstaller_web.exe. The same installer file will offer to download and install the required version 9.4 (R2018a) of the MATLAB Runtime, if not already installed on your machine. An example of input_parameters.txt file as well as a readme_dropcell.txt file will be automatically copied to the folder where you will choose to install the application. CRITICAL Read carefully the readme_dropcell.txt before first use of DropCell.exe. It describes the installation procedure as well as the input images naming rules.

\section{REAGENTS SETUP-}

\section{SILANE Solution}

To prepare $1 \%$ (vol/vol) silane solution, dilute $10 \mu \mathrm{l} 1 \mathrm{H}, 1 \mathrm{H}, 2 \mathrm{H}, 2 \mathrm{H}$-Perfluorododecyltrichlorosilane in $990 \mu$ f filtered HFE-7500 oil. This solution should be prepared immediately before use.

! CAUTION This solution is irritant and corrosive, work in a fume hood with appropriate materials.

CRITICAL Use this reagent immediately after preparation.

\section{Coupling buffer for boronic-based functionalization}

Dilute activation buffer 10 -fold in pure distilled water. This buffer should be freshly prepared before use.

\section{Storage buffer for boronic-based functionalization}

Dilute storage buffer 10 -fold in pure distilled water. This buffer should be freshly prepared before use.

\section{Quenching buffer for boronic-based functionalization}

$100 \mathrm{mM}$ ethanolamine in PBS. This buffer should be freshly prepared before use

! CAUTION This solution is corrosive and irritating; work in a fume hood.

CRITICAL Use this reagent immediately after preparation. Do not store.

\section{Blocking buffer for boronic-based functionalization}


Blocking buffer is $1 \%(\mathrm{vol} / \mathrm{vol})$ Dextran. Dilute dextran $20 \%(\mathrm{wt} / \mathrm{wt}) 20$-fold in pure distilled water to obtain $1 \%$ (vol/vol) blocking buffer. This solution can be stored at $4^{\circ} \mathrm{C}$ for up to 6 months.

! CAUTION: Dextran 20\% (wt/wt) is viscous pipette this solution very slowly.

\section{Cell buffer for sepsis application}

Heat the FBS at $56^{\circ} \mathrm{C}$ in a water bath for 35 minutes. Cool at room temperature $\left(20-25^{\circ} \mathrm{C}\right)$ and filter the serum using rapid-flow filter unit of $0.2 \mu \mathrm{m}$-PES membrane. Make 50-ml aliquots and store at $-20^{\circ} \mathrm{C}$. After thawing, centrifuge the serum at $3000 \mathrm{~g}$ for 10 minutes at room temperature to remove large debris. Supplement RPMI 1640 Glutamax with 10\% heat-inactivated FBS (vol/vol), 5\% Penicillinstreptomycin (vol/vol), and $20 \mathrm{mM}$ HEPES. Store culture medium at $4{ }^{\circ} \mathrm{C}$ and use it within 2 weeks after preparation.

\section{Blocking buffer murine IgG application}

$5 \%$ (vol/vol) Pluronic F-68 in PBS, sterile. Can be stored at $-20^{\circ} \mathrm{C}$ in small aliquots ready to use. For short term storage, store at $4^{\circ} \mathrm{C}$ for up to 4 weeks.

\section{Cell buffer 1 IgG application}

RPMI 1640 with Glutamax (w/o phenol red) supplemented with 10\% KnockOut Serum Replacement (vol/vol), 1x Penicillin-streptomycin, 0.1\% Pluronic F-127 (vol/vol), rHSA 0.5\% (wt/vol) and $25 \mathrm{mM}$ HEPES. Aliquot cell buffer and freeze at $-20^{\circ} \mathrm{C}$. For short term storage, store at $4^{\circ} \mathrm{C}$ for up to 1 week. Up to 4 weeks are possible when working in a sterile environment.

! CRITICAL: The use of rHSA and the removal of all products from animal origin reduces assay background and increases sensitivity.

\section{Immobilization reagent IgG application}

CaptureSelect ${ }^{\mathrm{TM}}$ Biotin Anti-LC-kappa (Murine) Conjugate (stock concentration $1 \mathrm{mg} / \mathrm{ml}$ ), diluted 1 to $5(\mathrm{v} / \mathrm{v})$ in PBS. Aliquot in $50 \mu \mathrm{l}$ and store at $-20^{\circ} \mathrm{C}$. For short term storage, store at $4^{\circ} \mathrm{C}$ for up to 4 weeks.

\section{PROCEDURE}

\section{Microfluidic device fabrication from existing molds. Timing $4 \mathrm{~h}$}

CRITICAL: Follow the instructions reported by Mazutis and colleagues ${ }^{35}$ to design microfluidic chips and fabricate the wafer mold (see Supplementary Data 1 for our wafer design). Ready-to-use wafer 
molds can be obtained from various commercially suppliers, thus avoiding photo-lithography steps (not described here, see reference ${ }^{70}$ ). Furthermore, finished droplet makers can be obtained directly from a variety of commercial suppliers such as Dolomite, Elveflow and others, avoiding steps 1-22. If purchased, droplet makers should be capable of forming $50 \mathrm{pL}$ droplets. $\mathrm{S}$

1. Place the wafer on a circular piece of aluminum foil (around $2 \mathrm{~cm}$ larger diameter than wafer). Form a cup around the mold.

2. Dust-off the wafer mold with compressed nitrogen or air.

! CRITICAL STEP Care should be taken to remove any dust that might form clumps in the channels.

3. Place the aluminum foil cup containing the mold in a petri dish.

4. Per wafer, pour $45 \mathrm{~g}$ of PDMS and $5 \mathrm{~g}$ of curing agent (9:1 PDMS/curing (wt/wt) agent ratio) in a disposable beaker, then vigorously mix with $1000 \mu \mathrm{l}$ pipette tip or plastic fork.

CRITICAL STEP Do not forget to add the curing agent; and mix generously. It is difficult to remove non- or semi-cured PDMS from the wafer mold.

5. Degas the PDMS-curing agent mixture using a vacuum chamber until all air bubbles are removed.

6. Slowly poor the degassed PDMS-curing agent mixture on top of the wafer from Step 3.

7. Put the Petri dish under vacuum again and degas the PDMS until no bubbles are visible. If bubbles persist, gently remove remaining bubbles with an air blower then cover the petri dish with lid to protect the PDMS from dust.

8. Bake the wafer mold-containing Petri dish in a drying oven at $65{ }^{\circ} \mathrm{C}$ for 90 to $120 \mathrm{~min}$ to harden the mixture.

9. Cool down to room temperature and carefully peel off the PDMS from the wafer using a scalpel. Clean the PDMS and wafer with clean nitrogen or air.

CRITICAL STEP The wafer is very fragile, any excessive pressure or bending force will break it. Wear protective glasses. Remove any under-flown cured PDMS first, and slowly remove PDMS by starting carefully, lifting the PDMS from the edges. The wafer can be re-used many times when handled properly.

PAUSE POINT The cured PDMS can be stored in a dust-free environment (petri dish) at room temperature for several months.

10. Place the PDMS on a cutting mat with the patterned side facing upward. Cut PDMS into separate microfluidic chips using a scalpel.

11. Punch with biopsy puncher (diameter $0.75 \mathrm{~mm}$ ) into the dedicated places (inlet and outlet holes, 4 per chip. See Supplementary Data 2 for the mask for the double-sided tape to prepare the observation chamber) to make outside connections.

\section{? TROUBLESHOOTING}


CRITICAL STEP The diameter of the biopsy puncher is critical. We use a $0.75 \mathrm{~mm}$-diameter biopsy

643 puncher to make inlet holes that fits tightly a $200 \mu \mathrm{l}$ pipette tip (for aqueous phases, Supplementary

644 Fig. 1) and $0.3 \mathrm{~mm}$ PTFE microtubing (for oil phase).

645 12. Cover both sides of the PDMS slab with frosted Scotch tape, and then peel off the tape from 646 both sides to remove PDMS debris that may be formed during punching. Alternatively, dust-off the 647 PDMS slaps with compressed air or nitrogen to remove any remaining PDMS debris.

648 CRITICAL STEP! Repeat step 12 if necessary. Care should be taken to remove any resulting PDMS 649 debris or dust that can otherwise clog the microfluidic chip.

650 13. Place a clean glass slide and the PDMS slab in the plasma chamber with the patterned side 651 facing upward.

652 14. Run the oxygen plasma program following the manufactory's recommendation. We use 30s 653 and 35 Watts.

\section{4 ? TROUBLESHOOTING}

655 15. Carefully remove the glass slide and PDMS slab from the plasma chamber; then bring the 656 treated surfaces into contact. Press the PDMS slab gently onto the glass slide to ensure uniform 657 bonding.

\section{8 ? TROUBLESHOOTING}

659 CRITICAL STEP To avoid microfluidic channel collapse and damage, only press gently on the PDMS 660 slab. If plasma activation is successful, the chip will attach almost by itself.

661 CRITICAL STEP Contact between PDMS slab and glass slide should be made quickly after plasma 662 exposition to avoid the hydrophobic reconstitution of PDMS (<5minutes). Be careful when placing 663 the PDMS, once contact is established, PDMS parts cannot be moved or removed.

664 16. Place the microfluidic device in the oven at $90^{\circ} \mathrm{C}$ for $5-20 \mathrm{~min}$.

665 CRITICAL STEP The chip needs surface treatment for the formation of droplets. Perform this step 666 directly after plasma treatment and bonding.

667 17. Remove the device from the oven, and cool down at room temperature.

668 18. Connect a 27-gauge needle to a $0.30 \mathrm{~mm}$ diameter PTFE microtubing using tweezers. Fill a 1 $669 \mathrm{ml}$ volume syringe with silane solution, afterwards attach a $0.22-\mu \mathrm{m}$ Millipore filter to the syringe. 670 Connect the needle-microtubing to the syringe-filter and fill the whole assembly with silane solution. 671 Prepare a second syringe filled with filtered HFE-7500 only.

672 ! CAUTION Use tweezers to hold the tubing. Take care to not pierce your skin.

673 ! CAUTION $1 \mathrm{H}, 1 \mathrm{H}, 2 \mathrm{H}, 2 \mathrm{H}$-Perfluorododecyltrichlorosilane is corrosive and highly irritant upon 674 inhalation. Work in a fume hood. Store the product under argon; or aliquot and freeze since the 675 silane will react with humid air rapidly and form crystals. 
676 19. Put the microtubing into the oil inlet and flush the microfluidic channels with silane solution 677 for about $10-30 \mathrm{sec}$.

678 20. After 1-minute incubation, flush the device with compressed clean air or nitrogen.

679 ! CAUTION Stay clear of aerosol; work under fume hood. We attach a $200 \mu \mathrm{l}$ pipette tip to the gas 680 outlet to facilitate the connection.

681 21. Repeat steps 19 to 21 twice with pure HFE7500 oil to wash the microfluidic device.

682 22. Check for dust inclusion of microfluidic device using light microscopy, especially at the orifice 683 for droplet generation. If dust is present, mark the chips and do not use them. Cover the PDMS chip 684 with Scotch tape.

685 ? TROUBLESHOOTING

686 PAUSE POINT The microfluidic chip can be stored in a close box at room temperature for several 687 months. Care should be taken to protect the devices from dust.

688 
23. Load the provided mask for the double-sided tape (see Supplementary Data 2 for the mask for the double-sided tape to prepare the observation chamber) into the cutting plotter.

24. Load the double-sided tape into the plotter and initiate the machine according to the user handbook.

25. Use the according plotter software (Graphtec or Silhouette Cameo) to send the design to the plotter. Use the following conditions for plotting using the Graphtec Cutting plotter:

\begin{tabular}{|l|l|}
\hline Parameter & Setting \\
\hline Offset & 0 \\
\hline Speed & 25 \\
\hline Acceleration & 1 \\
\hline Cut force & 21 \\
\hline Blade offset & 2.1 \\
\hline
\end{tabular}

697 And using Silhouette Cameo:

\begin{tabular}{|l|l|}
\hline Parameter & Setting \\
\hline Blade setting & 3 \\
\hline Speed & $5 \mathrm{~cm} / \mathrm{sec}$ \\
\hline Thickness & 33 \\
\hline
\end{tabular}

698

699

Plot the chamber design into the double-sided tape; cut with scissors into rectangles.

CRITICAL STEP The above settings will result in a plot that cuts the top protective layer and the double-sided tape, but not the bottom protective layer.

PAUSE POINT The cut tape can be stored in a close box at room temperature for several months.

Production of glass slides with access holes. TIMING 5 min per slide

26. Produce two holes (diameter around $1 \mathrm{~mm}$, see Supplementary Data 3 for the mask for laser

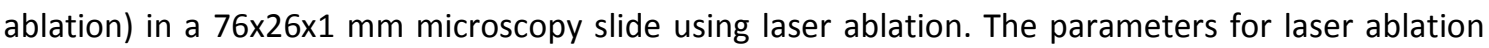
will depend on the type of the machine used. We use the AxysLaser with 95\% energy, 20 repetitions, and cluster $10 \mathrm{~mm}$ to speed up the process. CRITICAL STEP If laser ablation is not available, good alternatives are drilling, or sand-blasting. Take care to wear appropriate safety equipment when working with the glass.

27. Rinse and clean the glass slides with acetone. Repeat this process with isopropanol then

711 clean water. Dry with compressed air or nitrogen. Clean also a glass slide without holes (for the 712 bottom of the chamber). 
PAUSE POINT The glass slides can be stored in a close box at room temperature for several months.

\section{Microfluidic chamber assembly}

28. We use two variations of the same procedure to fabricate the droplet observation chamber. When using low numbers of beads ( $<500$ beads per droplets ; such as the sepsis application) follow Option A, when using high numbers of beads (> 500 beads per droplet ; such as for the murine IgG application) follow Option B. Both are based on the use of double-sided tape and glass slides. The principle difference between the procedures is the equipment needed to press the chamber (binder clips in Option A; thermos-press in Option B).

A) Sepsis application. TIMING 3-5 $h$

i) Take a nanoport and place it on one of the outlet holes of the top microcopy slide (from steps 26-

27). Use a 23-gauge needle to align the nanoport with the access holes on the glass slide (Fig. 2c).

ii) Add a drop of a UV-curable glue at the base of the nanoport and cure with UV light.

CRITICAL STEP This step must be performed carefully to avoid the clogging of the holes. Deposit a drop of viscous glue carefully which should be introduced between the slide and nanoport by capillary forces (Fig. 2c). Make sure not to move the nanoport during this process. ! CAUTION Wear appropriate eye and skin protection when using UV-light to cure the glue. iii) Repeat steps $i$ and ii for the second hole, and then expose the glass to oxygen plasma. iv) Cover the top slide with the patterned double-sided adhesive tape (Fig. 2c, from step 25) then bring the bottom slide (from step 27) into contact to form 2D incubation chamber. Gently press the glass the glass chamber to ensure uniform sealing.

734 v) Clamp the slides together using binder clips to seal the chamber (Fig. 2c)

735 vi) Incubate the clamped device for at least 2 hours at $90^{\circ} \mathrm{C}$.

736 vii) Cool the chamber to room temperature; and remove the clamps.

\section{7 ? TROUBLESHOOTING}

738 CRITICAL STEP Inspect the sealing quality with an optical microscope: well-sealed device should not 739 contain Saffman-Taylor fingers (Fig. 2d).

740 viii) Attach a magnet onto the bottom slide of the microfluidic chamber using double-sided 741 adhesive tape (Fig. 2e). Proceed to step 28.

742 CRTICAL STEP The magnet is $3 \mathrm{~mm}$ thick, which is convenient for images acquisition using the inverted microscope. Do not heat the magnet since heating may affect the magnetization.

744 ! CAUTION This magnet is very powerful and generate a strong magnetic flied (0.22T). Care should be taken during handling and keep the magnet away from objects that respond to magnetic field. 
i) Clean the two glass slides (top slide from steps 26-27 and bottom microscopy slide from step 27) in air plasma for $10 \mathrm{~min}$. If plasma is not available, this cleaning step can be replaced with frosted scotch tape or compressed air or nitrogen.

ii) Remove the protective layer from the shaped double-sided tape, and put the top slide (with holes) onto the adhesive tape. Flip, remove carefully the second layer and bring the bottom slide into contact to form 2D incubation chamber. Gently press the glass chamber to ensure uniform sealing. CRITICAL STEP Make sure to work clean and dust-free. In our experience, the tape tends to slightly adhere to the protective layers. To reduce this problem, the tape can be put at $-20^{\circ} \mathrm{C}$ before application. Remove carefully not to rupture or form deposits of tape. Deposits of tape will result in a chamber of incorrect height and the user will observe droplet movement during measurements.

iii) Transfer the assembly to the thermo-press, start and heat up the thermos-press to $150^{\circ} \mathrm{C}$.

iv) Put the assembly for 5 minutes at $150^{\circ} \mathrm{C}$, and press with 7 bars to achieve a chamber with a height of $33 \pm 2 \mu \mathrm{m}$.

! CAUTION Use appropriate safety equipment. The glass will be hot and might crack under pressure if deposits of dust, tape or other impurities are present.

v) Perform Step 28(A).i-ii to attach the two nanoports to the assembly.

vi) Attach magnets either on the side of the chamber with UV glue, or directly at the microscope using an appropriate support (see Supplementary Data 4 for the mask for the magnet holder). ! CAUTION This magnet is very powerful and generate a strong magnetic field. Care should be taken during handling and keep the magnet away from objects that respond to magnetic field. If beadlines appear to be points, the magnetic field is vertical instead of horizontal.

PAUSE POINT

\section{Surface treatment of the chamber. TIMING $10 \mathrm{~min}$}

29. Repeat step 18 and then connect the tubing to the nanoport using microtight fitting adapter.

30. Flush the chamber with $0.5-1 \mathrm{ml}$ silane solution, incubate for 1 to 3 minutes, completely flush with nitrogen and then fill with $1 \mathrm{ml} \mathrm{HFE7500} \mathrm{oil.} \mathrm{Close} \mathrm{the} \mathrm{assembly} \mathrm{with} \mathrm{two} \mathrm{caps} \mathrm{(Fig.} \mathrm{2e).}$

! CAUTION $1 \mathrm{H}, 1 \mathrm{H}, 2 \mathrm{H}, 2 \mathrm{H}$-Perfluorododecyltrichlorosilane is corrosive and highly irritant upon inhalation. Work in a fume hood.

31. Use one of the two following approaches to functionalize the nanoparticles. One approach uses boronic acid coupling via glycosyl groups on the antibody to immobilize the antibody on the 
nanoparticles to measure TNF- $\alpha$ secretion by single monocytes (Option A). The second approach uses the interaction between biotin and streptavidin to functionalize the beads to measure antibody secretion rate and affinity from single B cells (Option B).

A) Boronic acid coupling for sepsis application. TIMING $4 h$ and overnight incubation

i) Re-suspend the Carboxyl-Adembeads by pipetting and vortexing.

\section{? TROUBLESHOOTING}

787

! CRITICAL STEP Care should be taken to avoid foaming and bubble formation.

ii) Transfer $1 \mathrm{mg}(33.33 \mu \mathrm{l})$ of beads into a clean $1.5 \mathrm{ml}$ microtube.

! CAUTION Use low binding $1.5 \mathrm{ml}$ tube to perform bead functionalization.

iii) Add $100 \mu$ l of activation buffer and vortex gently.

iv) Place the tube in a magnet holder for about 1 minute at room temperature to pellet the beads.

v) Carefully discard the supernatant using a $200 \mu$ l pipette.

! CRITICAL STEP Do not disturb the bead pellet. A clear supernatant indicates a complete bead collection.

vi) Remove the tube from the magnet holder, and then vigorously resuspend the beads in $100 \mu \mathrm{l}$ activation buffer by vortexing.

CRITICAL STEP Care should be taken during washing steps. Do not allow beads to dry out. Drying reduces performances. After removing the supernatant, add buffer very quickly.

vii) Repeat steps iv - vi twice to complete the washing.

viii) Sonicate the beads for 3 minutes at room temperature at $30 \mathrm{~W}$ and $46 \mathrm{kHz}$. The beads are ready for EDC-sulfoNHS-based activation.

CRITICAL STEP Sonication breaks nanoparticle aggregates. The presence of aggregates reduces the efficiency of antibody coupling.

804 ! CAUTION Wear ear protection when sonicating beads.

805 ix) Put aliquots of EDC and sulfoNHS (see solution setup) to room temperature for 5 to 10 minutes and prepare $10 \mathrm{mg} / \mathrm{ml}$ solution for each.

x) Mix $0.5 \mathrm{ml}$ of EDC solution with $0.5 \mathrm{ml}$ of sulfoNHS solution to form a solution of $5 \mathrm{mg} / \mathrm{ml}$ of activated EDC-sulfo-NHS.

xi) Place the tube containing the beads in a magnet holder for about 1 minute; and carefully discard the supernatant.

xii) Re-suspend the beads in $1 \mathrm{ml}$ of activated EDC-sulfoNHS solution. Sonicate the beads for 3 minutes at room temperature.

xiii) Incubate for 20 minutes on a rotating wheel at room temperature.

xiv) Place the tube in a magnet holder for 1 min to pellet the beads. 
xv) Carefully discard the supernatant.

$816 \mathrm{xvi)}$ Add $100 \mu$ l of activation buffer to the beads (see solution setup).

817 xvii) Remove the tube from the magnet holder and mix well by vortexing.

818 xviii) Repeat steps xiv - xvii twice. The beads are now activated and ready to react with boronic 819 acid.

820 xix) Weigh out $50 \mathrm{mg}$ of 3-Aminophenylboronic acid hemisulfate and dissolve it in $1 \mathrm{ml}$ coupling 821 buffer (later referred to as BA solution).

822 xx) Place the tube in a magnet holder for 1 min to pellet the beads.

823 xxi) Carefully discard the supernatant.

824 xxii) Re-suspend the beads in $1 \mathrm{ml} \mathrm{BA}$ solution, and then sonicate them for 3 minutes at room 825 temperature.

826 xxiii) Incubate for 2 hours on a rotating wheel at room temperature.

827 xxiv) Place the tube in a magnet holder for about 3 minutes at room temperature.

828 xxv) Carefully discard the supernatant. Do not disturb the bead pellet.

829 xxvi) Add $100 \mu$ l of PBS to beads.

830 xxvii) Remove the tube from the magnet holder and mix well by vortexing.

831 xxviii) Repeat steps xxiv - xxvii twice.

832 xxix) Pellet the beads by placing the microtube in a magnet holder for $1 \mathrm{~min}$.

$833 \mathbf{x x x}$ ) Carefully discard the supernatant. Do not disturb the bead pellet.

834 xxxi) Re-suspend the beads in $500 \mu \mathrm{l}$ of $100 \mathrm{mM}$ ethanolamine to quench the reaction.

835 ! CAUTION Ethanolamine is an irritant substance; handle it carefully under a chemical hood.

836 xxxii) Sonicate for 3 minutes, and then incubate $30 \mathrm{~min}$ at room temperature on a rotating wheel.

837 xxxiii) Place the tube in a magnet holder for about 1 minute at room temperature.

838 xxxiv) Carefully discard the supernatant. Do not disturb the bead pellet.

839 xxxv) Add $100 \mu$ l of PBS to beads.

840 xxxvi) Remove the tube from the magnet holder and mix well by vortexing.

841 xxxvii) Repeat steps xxxiii - xxxvi twice.

842 xxxviii) Re-suspend the beads in $50 \mu \mathrm{l}$ PBS by vortexing, then sonicate for 3 minutes at room 843 temperature.

844 xxxix) Add $50 \mu$ g of antibody $(50 \mu \mathrm{l}$ of $1 \mathrm{mg} / \mathrm{ml})$ to $1 \mathrm{mg}$ of boronic-coated beads.

845 ! CAUTION The anti-TNF- $\alpha$ antibody is provided in PBS buffer without sodium azide and users should 846 work under a biological safety cabinet and aseptic conditions to avoid any contamination.

847 CRITICAL STEP For optimal coupling we recommend testing 10 to $50 \mu \mathrm{g}$ of antibody per mg of 848 boronic-coated beads. If other antibodies are used, this optimum might be different.

849 CRITICAL STEP Antibody coupling will only be successful if the antibody is glycosylated. 
CRITICAL STEP If other antibodies are used, these antibody solutions must be free from sodium azide, storage proteins or amine-based buffers (such as HEPES, MOPS, TRIS etc.) that could interfere with the coupling procedure. If present, the buffer needs to be exchanged using a desalting spin column or similar.

xl) Mix gently; then incubate overnight at $4{ }^{\circ} \mathrm{C}$ whilst gentle shaking.

xli) After overnight incubation, place the tube in a magnet holder for $1 \mathrm{~min}$ to pellet the beads.

xlii) Carefully discard the supernatant whilst not disturbing the bead pellet.

xliii) Add $100 \mu \mathrm{l}$ of PBS to beads.

xliv) Remove the tube from the magnet holder and mix well by vortexing.

xlv) Repeat steps xli-xliv twice.

xIvi) After washing, re-suspend the beads in $200 \mu \mathrm{l}$ storage buffer. The concentration of beads is 5 $\mathrm{mg} / \mathrm{ml}(1 \mathrm{mg}$ in $0.2 \mathrm{ml})$.

xlvii) Sonicate the beads for 1 to 2 minutes at room temperature and store the Ab-coated beads at $4^{\circ} \mathrm{C}$.

CRITICAL STEP Keep the beads at $4{ }^{\circ} \mathrm{C}$ and do not freeze. Freezing will cause the beads to aggregate and reduces the sensitivity of the bioassay.

PAUSE POINT The antibody-coated nanoparticles are stable for at least 2 months at $4^{\circ} \mathrm{C}$ without affecting the performance of the bioassay. Longer storage time will need to be determined by users. xIviii) For experiments, vortex the beads vigorously for 1 minute to re-suspend the formed pellet. xlix) Re-suspend $10 \mu \mathrm{L}$ of antibody-coated beads in $100 \mu$ l blocking buffer.

CRITICAL STEP Prior to using the beads in a binding assay, treat the beads with $1 \%$ dextran blocking solution ( $\mathrm{vol} / \mathrm{vol})$ to reduce non-specific binding.

I) Incubate for 45 minutes at room temperature, shaking at $700 \mathrm{rpm}$.

li) Place the tube in a magnet holder for about 1 minute to pellet the beads.

lii) Carefully discard the supernatant. Do not disturb the bead pellet.

liii) Add $100 \mu$ l of PBS buffer to beads.

liv) Remove the tube from the magnet holder and mix well by vortexing.

Iv) Repeat steps li - liv twice.

Ivi) After the washing step, sonicate the beads for $1 \mathrm{~min}$ at room temperature. Use immediately for the assay.

\section{B) Biotin-streptavidin coupling for the murine Ig G application. TIMING $2 \boldsymbol{h}$}

i) Re-suspend the Streptavidin plus-Adembeads by vortexing for $10 \mathrm{~s}$.

\section{? TROUBLESHOOTING}


ii) Per experiment, transfer $25 \mu \mathrm{l}$ of beads into a clean low-binding $1.5 \mathrm{ml}$ microtube. Add $25 \mu \mathrm{l}$ of PBS per $25 \mu$ l of nanoparticles.

! CRTICAL STEP Adapt accordingly if more or less nanoparticles are wanted in a droplet (see also Box 1 and 2).

iii) Add $2.5 \mu \mathrm{l}$ of Ig immobilization reagent stock to each $50 \mu \mathrm{l}$ bead solution. Deposit the drop at the top of the Eppendorf, and wash down with beads. Mix by pipetting, and incubate for 20-30 min at room temperature.

! CRITICAL STEP For other biotinylated Antibodies, add $5 \mu \mathrm{l}$ of a $0.5 \mathrm{mg} / \mathrm{ml}$ stock to $100 \mu \mathrm{l}$ nanoparticles volume. This might need optimization.

iv) Pellet the beads by placing the microtube in a magnet holder for about 1 minute.

v) Carefully discard the supernatant.

! CRITICAL STEP Do not disturb the bead pellet. A clear supernatant indicates a complete bead collection.

vi) Remove the tube from the magnet holder, and then vigorously re-suspend the beads in Blocking Buffer by using the respective volume (same total volume as used in step ii). Incubate for 20-30 $\min$.

CRITICAL STEP Care should be taken during washing steps to not loose particles due to inefficient resuspension or collection. Do not allow beads to dry out as drying reduces performance.

vii) Afterwards, repeat steps iv and v.

viii) Add Cell Buffer 1 (the same volume as used in step ii). Re-suspend the beads, and incubate for 20-30 minutes to block the bead surfaces.

PAUSE STEP: The beads can be stored overnight at $4^{\circ} \mathrm{C}$ after this step; and used on the next day.

ix) Shortly before experiments, repeat steps iv and $v$.

\section{Quality control of functionalized nanoparticles}

32. Assess the binding capacity of immobilized antibody using a fluorescent-based immune-sandwich assay in microtiter plates (bulk assay; Box 4) or within droplets. For the droplet microfluidic assay for the sepsis application, follow Option A. For the droplet microfluidic assay for the murine IgG application, follow Option B.

\section{A. Detection of TNF- $\alpha$ using a droplet microfluidic assay. Timing $2 h$}

CRITICAL: By following this protocol and the respective dilutions, this will lead to a beadline capacity of around $3 \mathrm{nM}$ within each droplet; and a number of nanoparticles of around 170 per droplet. 
i. Prepare the syringes for the protein solutions by connecting a $0.56 \mathrm{~mm}$ diameter PTFE microtubing to $200 \mu \mathrm{l}$ pipette tips using PDMS slabs $(6 \mathrm{~mm}$ diameter, with a hole in the middle of $0.75 \mathrm{~mm}$ diameter, see also Supplementary Fig. 1), and UV light NOA curing. Connect the tip-tubing assembly to a 27-gauge needle using tweezers, and then screw the needle to the syringe. Fill the whole system with HFE-7500.

ii. Prepare a second syringe for the reagents assay sample as described in step i.

iii. Prepare a syringe for the continuous phase by putting a 23-gauge needle on the syringe, then connect it to a $0.3 \mathrm{~mm}$ diameter PTFE microtubing using tweezers and fill the whole assembly with HFE-7500 oil containing $2 \%$ (wt/wt) fluorosurfactant.

! CRITICAL STEP Care should be taken to remove any air bubbles. If air bubbles are present, hold the syringe in a vertical position with the opening facing upwards and push the plunger until the air is completely removed.

iv. Mount the syringes on the syringe pumps and prime the assembly by applying a flow rate of $1000 \mu \mathrm{l} / \mathrm{h}$ for the reagent syringes to remove air bubbles from the assembly (syringes from step $\mathrm{i}$ and ii, reagent syringes) for about 30 seconds. The station is ready to load the samples.

v. Take antibody-coated beads from step 31(A).lvi, pipette $10 \mu \mathrm{l}$ of antibody-coated beads into new 1.5-ml tube and then sonicate for 3 minutes at room temperature.

\section{? TROUBLESHOOTING}

vi. Prepare the assay reagents for syringe 1 as follows: Add PE anti TNF- $\alpha$ antibody to a final concentration of $0.4 \mathrm{\mu g} / \mathrm{ml}$ (from $20 \mu \mathrm{g} / \mathrm{ml}$ stock) and antibody-coated beads at a concentration of $0.2 \mathrm{mg} / \mathrm{ml}$ (from $5 \mathrm{mg} / \mathrm{ml}$ stock) in cell buffer 2 . For each calibration point, prepare around $25 \mu$ l.

CRITICAL STEP Centrifuge the PE anti TNF- $\alpha$ antibody at $10,000 \mathrm{~g}$ for 5 minutes at $4{ }^{\circ} \mathrm{C}$ to remove aggregates.

vii. For syringe 2, prepare dilutions of recombinant TNF- $\alpha$ to desired concentration in cell culture media (0-100 nM).

\section{B. Detection of murine Ig $G$ using a droplet microfluidic assay. Timing $2 \boldsymbol{h}$}

CRITICAL: By following this protocol and the respective dilutions, this will lead to a beadline capacity of around $60 \mathrm{nM}$ within each droplet, and around 1,200 nanoparticles per droplet. Each concentration counts as an experiment, so prepare a sufficient volume of beads (Step 31(B)i-ix).

i) Follow Step 32(A).i-iv.

ii) Take the functionalized nanoparticles ( $25 \mu \mathrm{l}$ of nanoparticles per experiment) from step ix (Nanoparticle functionalization, option B, Biotin-streptavidin coupling for IgG application). Collect nanoparticles, discard supernatant and re-suspend the beads in the same volume of fresh cell buffer 1 . Add to the following reagents(all final concentrations): $150 \mathrm{nM}$ AffiniPure $F\left(a b^{\prime}\right)_{2}$ 
Fragment Rabbit Anti-Mouse IgG, Fcy fragment specific, $60 \mathrm{nM}$ Zenon $^{\mathrm{TM}}$ Alexa Fluor $^{\mathrm{TM}} 488$ Mouse IgG2b Labeling Kit; and $60 \mathrm{nM}$ fluorescent antigen of interest.

CRITICAL STEP Centrifuge the fluorescent proteins at $10,000 \mathrm{~g}$ for 5 minutes at $4{ }^{\circ} \mathrm{C}$ to remove big aggregates before taking the solution. As for the preparation of fluorescent molecules, refer to Box 1 and 2 .

CRITICAL STEP Over prolonged storage time, the beads will slowly sediment. Re-suspended every hour by using a pipette.

\section{? TROUBLESHOOTING}

iii) For calibration, prepare a dilution series of murine calibration Ig in cell buffer 1. Start with 200 $\mathrm{nM}$, and divide concentration by a factor of two down to $6.25 \mathrm{nM}$. Do not forget to prepare IgG cell buffer 1 with no added IgG as a blank measure.

CRITICAL STEP Before calibrating your own antibodies, we recommend to use murine control isotypes (such as supplied by ThermoFisher) for a general calibration of the system.

33. Generation of droplets. Place the pipette tips of the sample syringes in a sample tube (Supplementary Fig. 1), one in the desired concentration of calibration solution and the other in the final bead solution, and aspirate $25 \mu \mathrm{l}$ at $2000 \mu \mathrm{l} / \mathrm{h}$ rate of the beads and the calibration solution.

34. Connect the syringes to the corresponding inlet holes of the microfluidic device and connect the device outlet to waste with $0.30 \mathrm{~mm}$ diameter PTFE microtubing.

35. Set the flow rates of aqueous solutions and oil phase at $100 \mu \mathrm{l} / \mathrm{h}$, then start the pumps to inject fluids into the chip. Once the droplet production is stabilized and the fluid leaves the outlet (around 8-10 $\mu$ l volume used), increase the flow rate of oil to $300 \mu \mathrm{l} / \mathrm{h}$ to generate droplets of 50 $\mathrm{pL}$ volume.

36. In order to collect the droplets, connect the microfluidic device outlet to the incubation chamber (from step $28(\mathrm{~A})$ or $28(\mathrm{~B})$ according the application) using a new piece of $0.3 \mathrm{~mm}$ diameter PTFE microtubing. Attach the tubing to the nanoport of the observation chamber using microtight fitting adapter. Fill the chamber with droplets (visible as a grey, homogenous and turbid layer). Once filled, remove the tubing and fluid remaining in the nanoports, and close the chamber with the caps.

\section{? TROUBLESHOOTING}

CRITICAL STEP The loading of the cells in a pipette tips (rather than a syringe), the encapsulation process and the chamber filling should take less than $5 \mathrm{~min}$, and is typically performed at room temperature. If longer operating time is required, density-matching agents (such as OptiPrep, Percoll, Methyl Cellulose) can be added to the cell buffer. However, cells can also be cooled to $4^{\circ} \mathrm{C}$ to reduce 
secretion before encapsulation in droplets, if required, though this may slow secretion rate, at least initially, after encapsulating and changing to the desired temperature for secretion measurements. To cool, a small hole is drilled or punched into the bottom of a $2 \mathrm{ml}$ Eppendorf tube. The pipette tip is then introduced into the chip through the Eppendorf tube and glued in place. The volume between the pipette tip and the tube is filled with iced water during droplet loading.

CRITICAL STEP Clean the outside surfaces of the incubation chamber with isopropanol and water before filling. Apply Scotch tape to the glass chamber to remove residual dust particles.

37. Transfer the filled chamber to the microscope for imaging acquisition (Steps 38-45) and repeat steps 33-45 for all other calibration solutions.

\section{? TROUBLESHOOTING}

\section{Image acquisition. Timing $1 \mathrm{~h}$}

38. Start the epifluorescence microscope and set the heating at $37^{\circ} \mathrm{C}$ at least 30 minutes before starting acquisition.

CRITICAL STEP Care should be taken so that the experiment is performed at $37^{\circ} \mathrm{C}$ as the biological responses are optimal at this temperature. Imaging at room-temperature will result in a reduced cellular secretion rate and may also interfere with cellular secretion per se.

39. Open the acquisition software and set the image acquisition program. We typically perform quality controls of the droplets by acquiring manually a few images using a 10X objective (BF (20 ms), DAPI (300 ms - $1 \mathrm{sec})$, GFP (200 - $500 \mathrm{~ms})$, CY3 (200ms - $1 \mathrm{sec})$, and CY5 (200 - $500 \mathrm{~ms})$. Once acquisition exposure times have been defined, they should not be modified for a defined assay if a calibration curve is performed.

CRITICAL STEP Clean the objective before imaging.

CRITICAL STEP Exposure times will depend on the exact setup used, and may be adapted depending on the assay and reagents used. Fix exposure time to ensure absence of saturation and optimal fluorescence quantification.

\section{? TROUBLESHOOTING}

40. Position the chamber on the microscope stage insert (Supplementary Fig. 2).

- Chamber for sepsis application: When one magnet is attached to the chamber, place the chamber so that the magnet is located on the left when facing the microscope; the beadline is located in the left part of each droplet on the acquired bright-field image.

- Chamber for IgG application: Position the chamber on the microscope stage insert; and place the magnet holder above it so that the magnet is located in the front and back of the stage. Check with bright-field: The beadline should be located in the top or bottom part of each droplet and span over $2 / 3$ of the droplet diameters; and should be vertical or horizontal in orientation. 
41. Start the Perfect Focus System (PFS).

CRITICAL STEP This step is very critical as it allows maintaining the focus at different locations of the incubation chamber over time (corrects for potential drift of focus over time and scan).

42. Use the bright-field channel and adjust the focus manually so that the contours of droplets and beadlines appear as dark objects on the bright-field image (to facilitate automated detection).

CRITICAL STEP This step is very critical since sharp focus is needed for optimal signals as well as automated analysis.

43. Position the objective in the middle of the incubation chamber and then set up the imaging matrix to be acquired using the microscope software.

CRITICAL STEP Do not acquire images close to the magnet. Before imaging and after installation of the chamber, wait for 2-5 min for the temperature to equilibrate to reduce droplet movement due to this difference.

44. After the completion of the experiment, save the images as ND2 files and switch off the microscope and the heating system.

\section{? TROUBLESHOOTING}

45. At this step of the protocol, quality control of the images is needed. Potential issues are undesired movement of droplets during acquisitions, aggregation of nanobeads, irregular distribution of beads within the droplets, presence of clusters, more than one layer of droplet with the imaging microfluidic chamber (see Table 2 in the Troubleshooting section). Quality control movement: Open the images in the software, choose the bright field image and focus on a single field of view. Activate the time-lapse function, the software will show you the images over time. If no movement is visible $(<1 / 10$ of the diameter can be tolerated), repeat this step for two other fields of view. A small fraction of droplets $(<2 \%)$ might rearrange their position, these need to be removed manually or tracked.

Quality control droplets and layers: Similarly, the presence of droplets with varying diameter (>95\% should be similar in diameter) can be easily assessed by looking at the bright field images, as well as the presence of multiple layers of droplets. In the former case, some data might be useable, in the latter there is no other way than to repeat the experiment. We recommend repeating the experiment in both cases.

Aggregation of nanobeads: Aggregates of nanoparticles can also be seen in the bright field image. Usually, these are potato-shaped clusters that show bright fluorescence. Therefore, also check in the empty droplets where no secreting cell is present. These can lead to false-positive events (see also Troubleshooting Table 2).

Irregular distribution of beads within the droplets: This phenomenon can be checked in bright field; and the fluorescence channels. Often, this issue is accompanied by droplets showing different levels of fluorescence (brighter, darker droplets), and speaks for problems during encapsulation. We recommend repeating the experiment in this case. Presence of clusters: The presence of cell clusters can also be checked in bright field. A relatively easy control is to calculate the cells/droplet ratio, and compare the distribution of individual cells/droplets with the expected distribution following Poisson. If no other issues occur, this data 
1064 might still be usable, but is usually followed by an uneven distribution of dyes and antibodies as

1065 well /see above); making its analysis difficult.

1066

1067

1068 
Cell measurements.

46. The protocol can be used for a variety of different cells. The first application uses human monocytes from healthy donors and septic shock patients (Option A), whereas the second application uses murine IgG-secreting cells from immunized animals that were extracted from spleen and bone marrow (Option B). Other tissues or cell types can also be analyzed. However, cell preparation should be rapid and gentle, generating a singularized suspension of un-clumped

1077

\section{A) Sepsis application. TIMING $5.5 \mathrm{~h}$}

i) Start the laminar flow hood for cell culture 15 minutes before starting cell extraction.

1080

ii) Use EasySep Direct human monocyte isolation kit from STEMCELLS technologies to isolate highly pure CD14+ monocytes from human whole blood.

CRITICAL STEP This protocol allows for the isolation of live cells without using density gradient centrifugation or cell lysis buffers. For optimal recovery of monocyte isolation, use EDTA as an anticoagulant to collect blood samples. Follow EasySep Kit instructions to isolate monocytes from 3 $\mathrm{ml}$ of human blood.

1086

iii) After the end of the EasySep protocol, pipette $7 \mu \mathrm{l}$ to count the cells using FastRead 102 slides.

1087

iv) Add $20 \mu \mathrm{l}$ of the fluorescently labelled anti-CD14 antibody stock to the cells to stain monocytes.

1088

v) Incubate for 12 minutes at room temperature in dark.

1089

vi) Centrifuge the cells at $2800 \mathrm{~g}$ for 7 minutes at room temperature or $22-25 \mathrm{yy}^{\circ} \mathrm{C}$ and carefully remove the plasma from the cell pellet.

1091

CRITICAL STEP Carefully discard the supernatant. Do not disturb the cell pellet.

1092

CRITICAL STEP If residual red blood cells are present in the isolated cells, re-suspend the pellet in PBS

1093

for one additional separation step. The red blood cells can be also removed by lysis using Ammonium

1094

Chloride Solution from STEMCELL technologies (cat.no 07800).

1095

vii) Take antibody-coated beads from step 31(A)lvi, pipette $10 \mu$ of antibody-coated beads into new 1096 $1.5 \mathrm{ml}$ tube and then sonicate for 3 minutes at room temperature.

\section{? TROUBLESHOOTING}

1098

viii) Re-suspend at $10^{6}$ monocytes from step vi per $100 \mu$ l of cell culture buffer containing $20 \mathrm{mM}$

1099 HEPES. This is the final cell sample.

1100

1101

ix) To a separate volume of cell buffer 2 , add the following assay reagents (all final concentrations): $0.5 \mu \mathrm{g} / \mathrm{ml}$ LPS, $0.4 \mu \mathrm{g} / \mathrm{ml}$ PE anti TNF- $\alpha, 0.2 \mathrm{mg} / \mathrm{ml}$ antibody-coated nanoparticles, Nucview and Mitoview probes at $2 \mathrm{X}$. 


\section{? TROUBLESHOOTING}

CRITICAL STEP LPS is omitted for control experiment. Centrifuge the PE anti TNF- $\alpha$ antibody at 10,000 g for 5 minutes at $4{ }^{\circ} \mathrm{C}$ to remove aggregates.

x) Prepare the syringes for cell sample and reagent assay samples as described in Step 32(A)i.

xi) Prepare a syringe for the continuous phase as described in Step 32(A)iii.

! CRITICAL STEP Care should be taken to avoid air bubble formation. If air bubbles are formed, hold the syringe in a vertical position with the opening facing upwards and push the plunger until air bubbles are completely removed.

xii) Mount the syringes on the Nemesys pump and prime the assembly by applying a flow rate of $1000 \mu \mathrm{l} / \mathrm{h}$ for about $50 \mu \mathrm{l}$. Discard fluid. The station is ready to load the samples.

xiii) Place the pipette tips in the sample tubes containing cell sample and assay reagents separately (Supplementary Fig. 1) and aspirate $50 \mu \mathrm{l}$ at $2000 \mu \mathrm{l} / \mathrm{h}$ rate.

xiv) Connect pipette tips to the corresponding inlet holes of the microfluidic device and connect the device outlet to waste with $0.30 \mathrm{~mm}$ diameter PTFE microtubing.

xv) Set the flow rates of aqueous solutions and oil phase at $100 \mu \mathrm{l} / \mathrm{h}$ then start the pumps to inject fluids into the chip. Once droplet production is stabilized (1-2 $\mathrm{min})$, increase the flow rate of oil to $300 \mu \mathrm{L} / \mathrm{h}$ to generate droplets of $50 \mathrm{pL}$ volume.

\section{? TROUBLESHOOTING}

xvi) In order to collect the droplets, connect the microfluidic device outlet to the incubation chamber using new PTFE microtubing. Fill the chamber with droplets (visible as a gray, homogenous and turbid layer). Once filled, remove the tubing and fluid remaining in the nanoports, and close the chamber with the caps.

xvii) Immediately proceed to image acquisition as described in steps 38-45. In Step 39, use the following image acquisition settings: BF (20 ms), DAPI (1 sec), GFP (500 ms), CY3 (1 sec), and CY5 (500 ms) images using a 10X objective. 75 fields (25×3) every 30 minutes during 3 hours ( 7 time points). If a calibration curve is used for secretion, the same acquisition exposure times defined at step 39 need to be used.

\section{? TROUBLESHOOTING}

CRITICAL STEP If the chamber is not clean, wipe the surfaces with ethanol, or dust off using compressed air or scotch.

\section{B) Murine Ig-measurements application. TIMING $2 h$}


i) Prepare spleen, bone marrow or other organs of interest according to the established protocol of your laboratory, or follow reference ${ }^{38}$. Note that the cells should be well-suspended, and present as individual cells to proceed and give optimal results.

CRITICAL STEP In our experience, different protocols will result in slightly different secretion rates that are measured. Harsh conditions and protocols, i.e. strong shear forces or chemical stress, may result in decreased secretion rates.

ii) Count cells in the suspension, and centrifuge the volume equivalent of 2 million of cells. Resuspend the cells in PBS.

iii) Add $1 \mu \mathrm{l} / \mathrm{ml}$ of CellTrace Violet ( $5 \mathrm{mM}$ stock in DMSO); mix by pipetting and incubate the cells for $15-30 \mathrm{~min}$ at $37^{\circ} \mathrm{C}$. Dilute the cells afterwards in cell buffer 1 to quench the reaction.

iv) Take the beads from the assay from Step 32(B).ii

v) Centrifuge the labelled cells at $400 \mathrm{~g}$ for $5 \mathrm{~min}$ and carefully remove the supernatant from the cell pellet. Re-suspend gently but fully at $150 \mu \mathrm{l}$ of Cell buffer 1 . Proceed immediately to cell assay and encapsulation.

CRITICAL STEP The concentration of cells is optimized to result in the optimum amount of droplets containing an individual cell. Work fast, and proceed directly to the encapsulation since the cells will continue to secrete in bulk.

CRITICAL STEP The cellular density is quite high in this volume. For short term $(<1-2 \mathrm{~h})$, the cells can be stored on ice. Longer storage will result in a significant decrease in Ig secretion and cellular response.

\section{? TROUBLESHOOTING}

vi) Prepare the syringes for cell sample, bead solution as well as continuous phase as described in Step 32(A)i and Step 32(A)iii.

vii) Mount the syringes on the Nemesys pumps and prime the assembly by flowing $50 \mu$ lof solutions with a flow rate of $1000 \mu \mathrm{l} / \mathrm{h}$. Clean the pipette tips from oil by wiping them with tissue. No air bubbles should be visible now in the pipette tips.

viii) Place the syringes with added pipette tips in the sample tubes (Supplementary Fig. 1), one in the prepared cell suspension and the other in the final bead solution, and aspirate $50 \mu \mathrm{l}$ at $2000 \mu \mathrm{l} / \mathrm{h}$ rate of the beads and the calibration dilution.

ix) Connect the syringes to the corresponding inlet holes of the microfluidic device.

x) Set the flow rates of aqueous solutions and oil phase at $100 \mu \mathrm{l} / \mathrm{h}$ then start the pumps to inject fluids into the chip. Once the droplet production is stabilized, increase the flow rate of oil to 300 $\mu \mathrm{l} / \mathrm{h}$ to generate droplets of $50 \mathrm{pL}$ volume.

\section{? TROUBLESHOOTING}


1180

1181

1182

1183

1184

1185

1186

1187

1188

1189

1190

1191

1192

1193

1194

1195

1196

1197

1198

1199

1200

1201

1202

1203

xi) In order to collect the droplets, connect the microfluidic device outlet to the incubation chamber using a $0.30 \mathrm{~mm}$ diameter PTFE microtubing.

xii) Immediately proceed to image the droplets as described in steps 38-45. In Step 39, use the following image acquisition settings: DAPI (300 ms), GFP (200 ms), CY3 (200 ms), CY5 (200 ms) and BF (20 ms) images using a 10X objective. 100 fields of view (10x10) every 10 minutes during $60 \mathrm{~min}$ (7 time points). If a calibration curve is used for secretion, the same acquisition exposure times defined at step 39 need to be used.

\section{Automated image processing.}

47. For image processing of data obtained for the sepsis application, follow Option A. For image processing of data obtained for the murine IgG measurements, follow Option B.

\section{A) Sepsis application. TIMING $4 \mathrm{~h}$}

i) Extract images from ND2 files (Nikon file format) and save them in a TIFF format: 5250 images are extracted per experiment, including both the kinetics acquired with and without LPS.

ii) Open the input_parameter.txt file and set the required parameters (path to the folder containing the input images, vector of field numbers, vector of time points, various display and saving parameters, etc).

iii) Run the standalone Matlab application DropCell.exe (https://doi.org/10.6084/m9.figshare.11336663.v1).

CRITICAL STEP Image data without LPS and with LPS must be located in different folders and be analyzed separately.

CRITICAL STEP Make sure of the presence of five TIFF images per field in the input data folder, named according to the required naming rules.

CRITICAL STEP Make sure (by checking a few bright-field images) that the beadline is always located in the left-hand-part of the droplets, and that its length is lower than the third of the droplets diameter.

CRITICAL STEP Modify the input_parameters.txt carefully, observing format instructions.

CRITICAL STEP Do not open Excel while running DropCell.exe.

CRITICAL STEP Check the suitability of the analysis parameters on a few fields and time points before running the analysis of an entire experiment.

iv) Process the output STATdrops_sorting_YYYY-M-D_H-M-S.xIsx file obtained after the execution of DropCell.exe is completed. The Single-cell sheet focuses on the single-cell-containing droplet. CY3 relocalization fluorescence signal (signal-to-noise ratio) per droplet and time point is given in the columns "t**_Signal_CY3". "trackingfail_time", "rodfail_time", "death_time" and 
"phagocytosis_time" columns are used, when setting appropriate filters, to select the droplets of interest (single, live, and non-endocytic cell through the entire kinetics)

\section{B) Murine Ig-measurements. TIMING 3-4 h}

i) Extract images from ND2 files (Nikon file format) and save them in a TIFF format (Nikon file format; 1 TIFF file per time point) and transfer the images to the workstation for calculation.

ii) Open the Matlab script and run the provided script (Analyzer.m, https://github.com/LCMD$\mathrm{ESPCl} /$ dropmap-analyzer).

iii) A window will pop up. Within the first line, define the channels where you want to measure the beadline (as channel index within the file, see also readme file on the GitHub). Next, define the bright field channel; this will be used to detect the droplets. Define the number of time points and the average droplet radius in pixels. If you follow the protocol described herein, 25 pixels is a good a starting point for $50 \mathrm{pL}$ droplets.

CRITICAL STEP The algorithm is sensitive to the droplet diameter you define. You might need to increase or decrease the diameter if you change certain variables in the protocol.

iv) The output files are a Microsoft Excel file wherein every channel is a separate sheet, sorted by columns for beadline signal over time, average droplet signal over time and ratio of the two values over time. In addition, Matlab file where the images of the recognized droplets are saved by index.

v) Use the calibration curve to transfer ratios to concentration of analyte.

CRITICAL STEP Be sure to take the right curve for the proper channel.

vi) Please refer to Box 2 for the extraction of parameters. Sort and select droplets of interest in a separate sheet and combine the information.

vii) After analysis, check the selected droplets with the verify function (verify.m) to exclude falsepositive events. The verif program will show the droplets to verify their content. It will ask for a list of indices to check.

CRITICAL STEP Control the selected events for false-positive events (dead cells or other); and exclude those from further analysis.

\section{Chamber cleaning after experiments. TIMING 5 min}

CRITICAL If desired, the chambers can be used over 4-8 weeks for multiple experiments. After the measurements, the droplets should be removed from the chamber before storage.

48. Repeat step 18 but fill the syringe with HFE7500 oil. Connect the tubing to the nanoport using microtight fitting adaptors.

49. Flush the chamber with $1 \mathrm{ml} \mathrm{HFE7500} \mathrm{oil} \mathrm{to} \mathrm{remove} \mathrm{droplets.}$ 
1237 50. Close the nanoport chamber with caps and keep it in a dust-free environment.

1238 
1240 Troubleshooting guidance can be found in Table 2.

Table 2. Troubleshooting Table.

\begin{tabular}{|c|c|c|c|}
\hline Step & Problem & Possible reason & Solution \\
\hline 11 & $\begin{array}{l}\text { Cracking in the inlets or } \\
\text { outlets during punching. }\end{array}$ & $\begin{array}{l}\text { Blunt or clogged } \\
\text { puncher. } \\
\text { Insufficient mixing of } \\
\text { PDMS and curing } \\
\text { agent. }\end{array}$ & $\begin{array}{l}\text { Use a new puncher. } \\
\text { Vigorously mix PDMS and curing } \\
\text { agent to achieve a homogenous } \\
\text { mixture of the two components. Do } \\
\text { not cure for prolonged times (> } 24 \mathrm{~h} \text { ). }\end{array}$ \\
\hline 14 & $\begin{array}{l}\text { Microfluidic device } \\
\text { delaminates during } \\
\text { surface treatment. }\end{array}$ & $\begin{array}{l}\text { Plasma protocol was } \\
\text { not optimal. } \\
\text { Not sufficiently } \\
\text { cleaned glass slides. }\end{array}$ & $\begin{array}{l}\text { Check and adapt the parameters of } \\
\text { your plasma procedure. } \\
\text { Use clean glass slides: wash the glass } \\
\text { slides with acetone, isopropanol, milli- } \\
\text { Q water. Repeat if necessary. }\end{array}$ \\
\hline $\begin{array}{l}15,18- \\
22\end{array}$ & $\begin{array}{l}\text { No droplet formation } \\
\text { during experiments. }\end{array}$ & $\begin{array}{l}\text { Collapsed } \\
\text { microfluidic } \\
\text { channels. } \\
\text { Aqueous solutions } \\
\text { wet the microfluidics } \\
\text { channels. } \\
\text { Dirt present within } \\
\text { the microfluidic } \\
\text { assembly. } \\
\text { Absence of sufficient } \\
\text { concentration of } \\
\text { surfactant. }\end{array}$ & $\begin{array}{l}\text { Reduce force when sealing PDMS slab } \\
\text { to glass slide. } \\
\text { Repeat the surface treatment of the } \\
\text { device. } \\
\text { Observe microfluidic chips after } \\
\text { fabrication for crystal formation, or } \\
\text { the presence of dust particles. } \\
\text { Use HFE7500 with added } 2.0 \% \\
\text { fluorosurfactant-008. }\end{array}$ \\
\hline
\end{tabular}




\begin{tabular}{|c|c|c|c|}
\hline $\begin{array}{l}28(A) \\
\text { i-vii. }\end{array}$ & $\begin{array}{l}\text { Microfluidic chamber } \\
\text { leakage. }\end{array}$ & Inefficient sealing. & $\begin{array}{l}\text { Use clean glass slides and work clean. } \\
\text { Increase the duration of incubation } \\
\text { during step } 28 \text { (A) vi. } \\
\text { Make sure that the nanoports are well } \\
\text { sealed with UV glue. }\end{array}$ \\
\hline $\begin{array}{l}36,46 \\
\text { (A) } x v i, \\
45\end{array}$ & $\begin{array}{l}\text { Observed movement of } \\
\text { droplets during } \\
\text { acquisitions. }\end{array}$ & $\begin{array}{l}\text { Droplet coalescence } \\
\text { occurs. } \\
\text { Chamber height is } \\
\text { bigger than droplet } \\
\text { diameter. }\end{array}$ & $\begin{array}{l}\text { Increase the concentration of } \\
\text { surfactant. } \\
\text { Fabricate a chamber with proper } \\
\text { height (<90\% of droplet diameter). } \\
\text { Make sure that the height of the } \\
\text { chamber is optimal for your droplet } \\
\text { volume. }\end{array}$ \\
\hline $\begin{array}{l}31(A) i \\
\text { and } 31 \\
(B) i\end{array}$ & & $\begin{array}{l}\text { Presence of air } \\
\text { within the chamber. } \\
\text { Microfluidic } \\
\text { chamber is leaking. }\end{array}$ & $\begin{array}{l}\text { Remove air bubbles before acquiring } \\
\text { images. } \\
\text { Check steps } 27 \text { and } 28 \text { (A) i-vii. }\end{array}$ \\
\hline & $\begin{array}{l}\text { Aggregation } \\
\text { nanobeads. }\end{array}$ & $\begin{array}{l}\text { Inherent to the } \\
\text { beads. } \\
\text { Long term storage of } \\
\text { beads. }\end{array}$ & $\begin{array}{l}\text { Increase sonication time. } \\
\text { It should be noted that extended } \\
\text { sonication time, can heat the } \\
\text { nanoparticles denaturing the } \\
\text { functionalized antibodies. Ice can be } \\
\text { added to the bath to limit } \\
\text { nanoparticle overheating. }\end{array}$ \\
\hline $\begin{array}{l}32 \text { (A) } \\
i, \quad 32 \\
\text { (B) i, } \\
37,46 \\
\text { A) vii }\end{array}$ & $\begin{array}{l}\text { Irregular distribution of } \\
\text { beads within the } \\
\text { droplets, presence of } \\
\text { clusters. }\end{array}$ & $\begin{array}{l}\text { Beads aggregates } \\
\text { during coupling. }\end{array}$ & $\begin{array}{l}\mathrm{COOH} \text { beads: increase sonication } \\
\text { time. } \\
\text { Streptavidin-beads: Bead-crosslinking } \\
\text { due to over-biotinylated } \\
\text { immobilization reagent. After step } 31 \\
\text { (B) iii, add } 10 \mu \mathrm{M} \text { biotin before }\end{array}$ \\
\hline
\end{tabular}




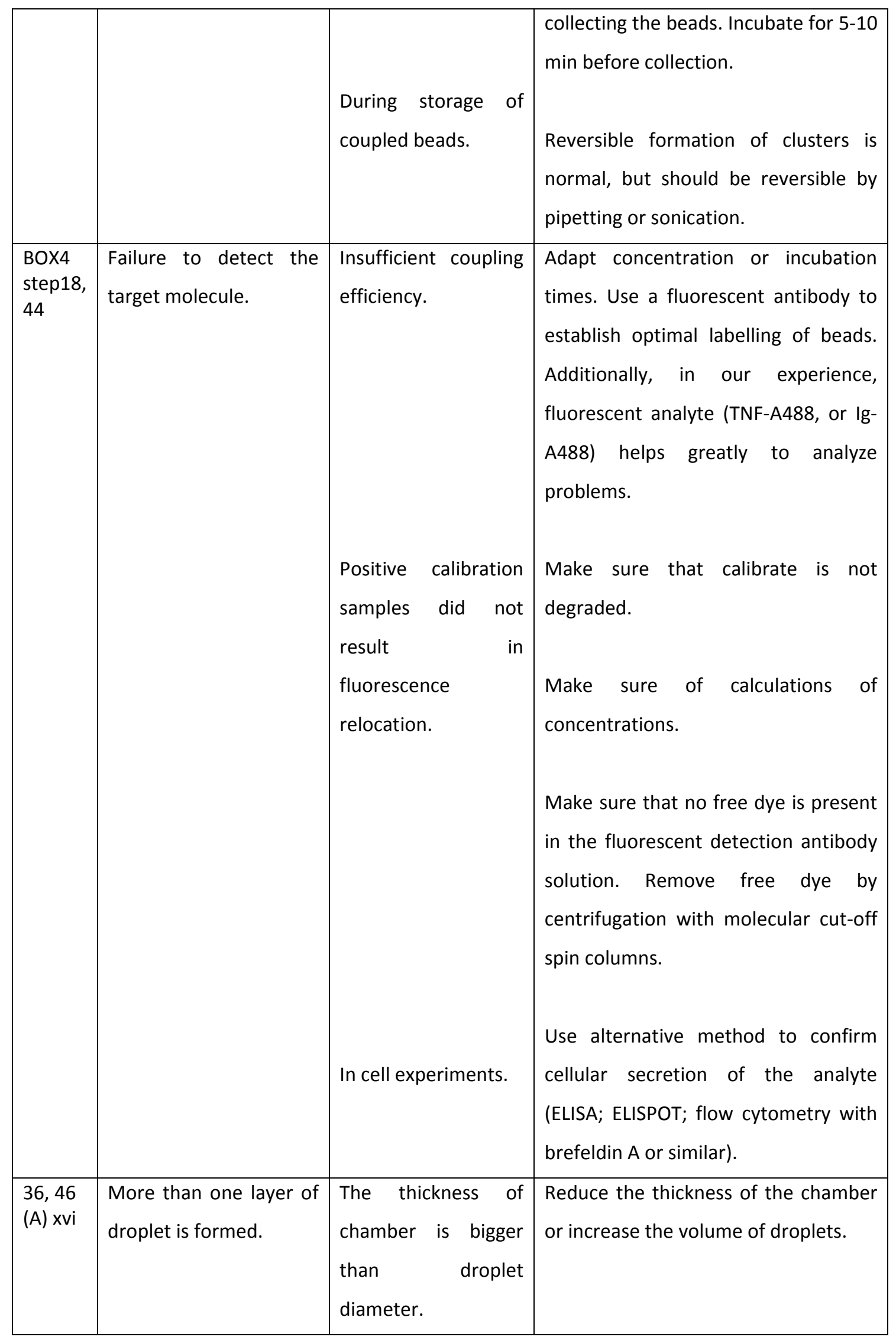




\begin{tabular}{|l|l|l|l|}
\hline $\begin{array}{l}46(\mathrm{~A}) \\
\mathrm{xv} \\
46(\mathrm{~B}) \mathrm{i}\end{array}$ & $\begin{array}{l}\text { Cell aggregates and } \\
\text { clumps are present in } \\
\text { the microfluidic chip } \\
\text { during encapsulation. }\end{array}$ & $\begin{array}{l}\text { Nucleic acids are } \\
\text { released from dead } \\
\text { cells. }\end{array}$ & $\begin{array}{l}\text { Add Benzonase to cell suspension for } \\
\text { DNA and RNA removal. }\end{array}$ \\
\hline $\begin{array}{l}46 \text { (A) } \\
\text { ix }\end{array}$ & $\begin{array}{l}\text { Cells are not } \\
\text { fluorescent. }\end{array}$ & $\begin{array}{l}\text { Cells are necrotic. } \\
\text { Live and dead cells } \\
\text { staining protocol is } \\
\text { not optimal. }\end{array}$ & $\begin{array}{l}\text { Discard these cells from the analyses. } \\
\text { Use a probe that can detect necrotic } \\
\text { Optimize the concentration of } \\
\text { live/dead probes. }\end{array}$ \\
\hline $39-45$ & $\begin{array}{l}\text { Rapid decrease of } \\
\text { droplet and beadline } \\
\text { fluorescence }\end{array}$ & $\begin{array}{l}\text { Photobleaching } \\
\text { Optimally, reduce illumination } \\
\text { intensity and/or exposure time. } \\
\text { Otherwise, reduce the total number } \\
\text { of time points. }\end{array}$ \\
\hline
\end{tabular}




\section{TIMING}

1247 Steps 1-22

1248 Steps 23-30

1249

1250

1251

1252

1253

1254

1255

1256

1257

1258

1259

1260

1261

1262

1263

1264

1265

1266
Droplet maker fabrication $\quad 4 \mathrm{~h}$

Observation chamber fabrication 2-5 h

Microfluidic chamber assembly

28(A) Sepsis application.

\section{3-5 h}

28(B) Murine IgG application.

$1.5 \mathrm{~h}$

Nanoparticle functionalization

31(A) Boronic acid coupling

4h, ON incubation

31(B) Biotin-streptavidin coupling

$2 \mathrm{~h}$

Quality control of functionalized nanoparticles

BOX 4 Microtiter plate assay $3 \mathrm{~h}$

32(A) Detection of TNF- $\alpha$ droplet assay $2 \mathrm{~h}$

32(B) Detection of murine IgG droplet assay 2h

Steps 33-45 Droplet generation and image acquisition $1 \mathrm{~h}$

Steps 46(A) - 46(B) Cell measurements.

46A) Sepsis Application 5.5h

46B) Murine Ig-measurements application 2h

Steps $47(A)-47(B) \quad$ Automated Image processing.

47(A) Sepsis application $\quad 4 \mathrm{~h}$

47(B) Murine Ig-measurements 3-4h 


\section{Anticipated results}

1268 The DropMap system is a flexible platform for high-throughput single-cell phenotypic analysis that is 1269 particularly well adapted to the characterization of immune responses. The protocol can be modified 1270 to allow the single cell quantitative analysis of a wide range of cell-surface markers and secreted 1271 molecules expressed by a range of different cells types, simultaneously with other cellular 1272 characteristics such as endocytosis and viability. The development described here expands its 1273 potential from the analysis of humoral to cell-mediated and innate immune responses.

The ability of DropMap to simultaneously measure secretion rates and affinities of antibodies from thousands of single B cells makes it a powerful tool to study humoral immune responses ${ }^{38}$, for example following vaccination ${ }^{71,72}$ or infection. Furthermore, the large data sets from these singlecell experiments are well adapted as training sets for deep learning/artificial intelligence strategies, and allow in silico modeling and simulation of the immune responses following vaccination. Such strategies could ultimately contribute to the reduction or replacement of animal experiments.

The system is also well adapted to study the role of T cells in both humoral and cell-mediated immune responses. Given their constitutive role in immune-surveillance, aberrant $\mathrm{T}$ cell functions are linked to autoimmune diseases as well as to carcinogenesis and to defective protection against pathogen infections ${ }^{73,74}$. In this protocol, we demonstrate our approach by integrating the measurement of secretion of a range of murine and human cytokines produced by $T$ cells identified using a fluorescent anti-CD3 antibody. For example, we show here the measurement of secretion rates of TNF- $\alpha$, IFN- $\gamma$, IL-2 and IL-4 from human T cells (Fig. 5, LODs of $10.4 \mathrm{nM}, 0.6 \mathrm{nM}, 0.5 \mathrm{nM}$ and $0.2 \mathrm{nM}$ for human IL-2, IL-4, TNF- $\alpha$ and IFN- $\gamma$, respectively). Distribution of secretion rates are shown for ex vivo stimulated and unstimulated peripheral blood mononuclear cells (PBMCs; stimulated with PMA/lonomycin). Interestingly, stimulation with PMA/ionomycin did not significantly affect the median secretion rates for TNF- $\alpha$ ( $N=4$ independent experiments, unstimulated $25 \pm 13$ molecules/s; stimulated $28 \pm 15$ molecules/s, p-value 0.77 , mean \pm standard deviation of the median values for the independent experiments, two-tailed unpaired t-test), but significantly increased the percentage of secreting $T$ cells by around 8 -fold (from $2.5 \pm 0.6 \%$ to $17 \pm 11 \%$, mean \pm standard deviation, p-value 0.05 , twotailed unpaired t-test, Fig. 5a). In contrast, upon stimulation, there were significant increases in the frequency and secretion rates of T cells secreting INF- $\gamma$ ( $N=4$ independent experiments, $1 \pm 1 \%$ vs. 19 $\pm 5 \%$, p-value 0.004 ; and $4.7 \pm 2.8$ molecules/s vs. $22.5 \pm 12.8$ molecules/s, $p$-value 0.03 , both mean \pm standard deviation of the median values for the independent experiments, two-tailed unpaired $t$ - 
1300 viral infections ${ }^{75-77}$. The average median rate of IL-2 secretion by $T$ cells ( $N=3$ independent 1301 experiments, $0 \pm 1.1 \%$ vs. $24 \pm 10 \%$, p-value 0.01 , mean \pm standard deviation; and $43 \pm 5$ 1302 molecules/s vs. $73 \pm 18$ molecules/s, p-value 0.05 , mean \pm standard deviation of the median values 1303 for the independent experiments, two-tailed unpaired t-test, Fig. 5c) was equivalent with or without 1304 stimulation, while a 10-fold increase of the frequency of IL2 secreting cells was found in the 1305 stimulated sample. A low frequency $(<2 \%)$ and low (but measurable) secretion rates ( $\mathrm{N}=3$ 1306 independent experiments, $0.6 \pm 0.7 \%$ vs. $1.7 \pm 0.7 \%$, non-significant in a two-tailed unpaired t-test, 1307 mean \pm standard deviation; and $4.4 \pm 3.2$ molecules/s vs. $4.2 \pm 2.7$ molecules/s, non-significant in a two-tailed unpaired t-test, mean \pm standard deviation of the median values for the independent experiments, Fig. 5d) were observed for IL-4 secreting cells in both samples. The detection of IL-4 at low expression level in a small subset of cells nicely illustrates the advantages of DropMap, and its use for the analysis of cytokine secretion by T cells at the single-cell level. This opens up new opportunities to improve our fundamental understanding of immune responses, for example to study $\mathrm{T}$ cell plasticity ${ }^{78}$, which may lead to the development of novel therapeutic strategies. It is also a promising approach for clinical single-cell immuno-monitoring for patient stratification and personalized medicine.

We also extend the DropMap system to analyse the innate immune responses and to monitor the dysfunction of monocytes from septic shock patients (Table 1). Septic shock is the most severe form of sepsis $^{79,80}$. Sepsis is a complex clinical syndrome characterized by an early dysregulated inflammatory response. This response, triggered by the recognition of microbial patterns by receptors such as Toll-like receptors (TLR), is often followed by a post-infective complex immune dysfunction combining innate and adaptive immune defects, such as monocyte dysfunction, characterized by decreased TNF- $\alpha$ production and release ${ }^{81}$.

1323 To evaluate the potential of DropMap in this context, we first controlled its ability to maintain viable primary human monocyte population in a confined environment over the course of an experiment with and without pro-inflammatory lipopolysaccharide (LPS). For all experiments, only a small fraction of cells showed apoptotic activity $(0.49 \pm 0.09 \%$ for $\mathrm{N}=3$ healthy donors and $1.94 \pm 1.75 \%$ for $\mathrm{N}=3$ septic patients, mean \pm standard deviation for the independent experiments, Table 3 ), demonstrating that the encapsulation process allows functional analysis.

Deactivation of circulating monocytes is currently viewed as the soundest indicator of sepsis-induced immunosuppression $^{79,80}$ and reduced production rate of TNF- $\alpha$ by monocytes in bulk, upon in vitro stimulation by LPS, is used a biomarker to monitor sepsis-induced immunosuppression in intensive 
the functionality of septic patients' immune system. Here, we show that the DropMap system can be used to assess TNF- $\alpha$ secretion rate of single monocytes from septic shock patients in response to LPS stimulation.

In agreement with previous studies ${ }^{22}$, single-cell DropMap measurements revealed lower rates of TNF- $\alpha$ secretion by monocytes upon LPS activation in septic shock patients ( $N=3$ patients, $1.3 \pm 0.5$ molecules/s, mean \pm standard deviation of the median values for the independent experiments) compared to healthy donors ( $\mathrm{N}=3$ donors, $2.5 \pm 1.1$ molecules/s, mean \pm standard deviation of the median values for the independent experiments, Fig. 6a and Table 3). Without LPS, only a small fraction (3\%) of monocytes secrete TNF- $\alpha$ ( $N=1$ donor, $n=32$ monocytes, $0.9 \pm 0.4$ molecules/s, mean \pm standard deviation) demonstrating that cell activation is specifically trigged by LPS stimulation (Fig. 6b). Interestingly, the frequency of monocytes, having a TNF- $\alpha$ secretion rate below 0.5 molecules per second (i.e. below the limit of detection of the bioassay), was higher in septic shock patients ( $N=3$ patients, $29 \pm 8 \%$, mean \pm standard deviation for the independent experiments), than in healthy donors ( $\mathrm{N}=3$ donors, $6 \pm 6 \%$, mean \pm standard deviation for the independent experiments). These differences were at the limit of statistical significance ( $p=0.05$ with one-sided Mann-Whitney test) (Fig. 6c).

Furthermore, monocytes from sepsis patients have been reported to exhibit higher endocytic activity compared to healthy donors ${ }^{82}$. The uptake of nanobeads is usually used as a readout for functional phenotyping of cell endocytosis ${ }^{83-85}$. We thus used the DropMap platform to monitor over time the uptake of nanobeads (endocytic activity) by monocytes. As expected, we observed differences in nanobead uptake between cells of healthy donors ( $N=3$ donors, $29 \pm 3 \%$, mean \pm standard deviation for the independent experiments) and septic shock patients ( $N=3$ patients, $56 \pm 15 \%$, mean \pm standard deviation for the independent experiments, Table 3). These differences were at the limit of statistical significance ( $p=0.05$ with one-sided Mann-Whitney test). This result should be taken cautiously given the small number of samples. Overall, these results are exemplifying the potential application and added value of the DropMap technology in clinical studies.

The DropMap system is a valuable tool for monitoring cell responses and probing heterogeneity with single-cell resolution that can be applied in the field of immuno-monitoring, and beyond, to address a large panel of fundamental research or clinical questions. It is robust and simple, and it can be easily adapted to measure other cell types, in healthy and diseased states, and to measure other secreted molecules (such as microRNAs, other cytokines, chemokines and enzymes). 

DropMap.

1367 Number of LPS stimulated cells per experiment, percentage of dead cells, secretion rate 1368 (molecules/sec), percentage of low secreting cells, and the percentage of endocytic cells of 3 healthy 1369 donors and 3 septic shock patients. Dead monocytes were determined by measuring caspase-3 activity in droplets. Endocytic activity was assessed by counting the number of single monocytes that bind to or internalize the magnetic beadline.

1372

\begin{tabular}{lccccc}
\cline { 2 - 6 } & Cell number & Dead cells (\%) & $\begin{array}{r}\text { Secretion rate } \\
\text { (molecules/s) }\end{array}$ & Low secreting cells (\%) & Endocytic cells (\%) \\
\hline Healthy Donor 1 & 2215 & 0.6 & 3.6 & 1.8 & 31 \\
Healthy Donor 2 & 3008 & 0.5 & 2.5 & 5.3 & 31 \\
Healthy Donor 3 & 4495 & 0.4 & 1.4 & 13.3 & 26 \\
Septic Patient 1 & 2473 & 1.6 & 0.9 & 34.1 & 61 \\
Septic Patient 2 & 1122 & 3.8 & 1.9 & 20.0 & 69 \\
Septic Patient 3 & 3077 & 0.4 & 1.0 & 31.9 & 39 \\
\hline
\end{tabular}

1373

1374

1375

1376 
When choosing a new pair of antibodies to set up another immunoassay, we use consider the following, ranked approaches:

1381 1) Study literature and/or suppliers for antibody pairs that are tested for sandwich 1382 immunoassays.

1383 2) A neutralizing and a non-neutralizing clone will recognize different epitopes, and binding 1384 interference is less likely.

1385 3) The combination of polyclonal IgG for immobilization and monoclonal IgG for detection can 1386 also show good results, although recalibration is necessary when different batches of antibody are 1387 used.

1388 4) Use a variety of different monoclonal antibodies and test the various combinations.

1389

\section{Labelled antigens and antibodies:}

1391

Important points to consider when preparing the reagents for the in-droplet assay:

1392

- $\quad$ Purify antibodies and antigens as much as possible. Pure reagents will allow for better results and more standardized and repeatable results.

1394

- $\quad$ Be sure to remove any free dye or biotin before using the proteins in the assays. Any non1395 bound molecules will increase the background and reduce the sensitivity of the assay. We use several rounds centrifugation and 10K MWCO Protein Concentrators (Thermo Scientific ${ }^{\mathrm{TM}}$ Pierce $^{\mathrm{TM}}$ ) to remove

1397 free dyes.

- When labelling the antigen with biotin or fluorescent dye, use a random method to conserve 1399 all available epitopes on the antigen.

1400 - Do not over-label proteins. We aim for a degree of labelling (molecules/protein) of around 2.

1401 Over-labelled antigens will not allow to set-up sensitive immunoassays.

1402 - After labelling and purification, determine the exact concentration of the protein since the 1403 bioassay performance it highly variable with concentration.

- $\quad$ Test the labelled proteins in an ELISA format to determine the absence of interference. For antigens, we usually assay this by ELISA. Coat the labelled and un-labelled antigen on the ELISA plate (separately), and add the antibody in varying concentration. Compare both binding curves. 
1409 The in-droplet assay allows for a wide range of measurements. The assay can be set up to be very sensitive (LOD of 500 molecules); or to span a wider concentration range. Use bulk measurements that help set up single-cell measurements. Look for literature values of bulk measurements that indicate the number of cells, time, volume and concentrations of the experiment to estimate the secretion rate. This crude estimation can serve as a starting point for assay set up.

There are four determining factors to set up the assay: concentration of beads, immobilization reagent, detection reagent and the apparent dissociation constant of the pair of antibodies for capture and detection. For starting values, please refer to the table below.

\begin{tabular}{|c|c|c|c|c|}
\hline Parameter & $\begin{array}{l}\text { Number of } \\
\text { nanoparticles }\end{array}$ & $\begin{array}{l}\text { Immobilization } \\
\text { antibody }\end{array}$ & $\begin{array}{l}\text { Labelled } \\
\text { detection } \\
\text { antibody }\end{array}$ & $\begin{array}{l}\text { Apparent } \\
\text { dissociation } \\
\text { constant of } \\
\text { capture and } \\
\text { detection } \\
\text { antibodies }\end{array}$ \\
\hline $\begin{array}{l}\text { Influence on } \\
\text { capacity of the } \\
\text { beads }{ }^{\#}\end{array}$ & +++ & +++ & - & - \\
\hline $\begin{array}{l}\text { Influence on } \\
\text { sensitivity }\end{array}$ & + & +++ & +++ & ++ \\
\hline $\begin{array}{l}\text { Influence on } \\
\text { measurement } \\
\text { range }^{\#}\end{array}$ & ++ & ++ & ++ & + \\
\hline $\begin{array}{l}\text { Use of too much } \\
\text { will result in... }\end{array}$ & $\begin{array}{l}\text { Plateau in the } \\
\text { calibration curve. } \\
\text { Great for Yes/No } \\
\text { answers, less } \\
\text { suitable to } \\
\text { quantify } \\
\text { secretion rates } \\
\end{array}$ & Increased waste & $\begin{array}{l}\text { Decreased } \\
\text { sensitivity; } \\
\text { increased LOD }\end{array}$ & N.A. \\
\hline Use of too little... & $\begin{array}{l}\text { Absence of } \\
\text { beadline; no } \\
\text { reliable } \\
\text { measurement of } \\
\text { relocation }\end{array}$ & $\begin{array}{l}\text { Plateau in the } \\
\text { calibration curve. } \\
\text { Great for Yes/No } \\
\text { answers, less } \\
\text { suitable to } \\
\text { quantify } \\
\text { secretion rates }\end{array}$ & $\begin{array}{l}\text { Lower relocation } \\
\text { values }\end{array}$ & N.A. \\
\hline Ideally & $\begin{array}{l}\text { Binding capacity } \\
\text { matches the } \\
\text { quantity of } \\
\text { labelled } \\
\text { detection reagent }\end{array}$ & $\begin{array}{l}\text { Calculated as 1- } \\
2 x \text { capacity of the } \\
\text { beads (minimized } \\
\text { waste) }\end{array}$ & $\begin{array}{l}\text { Matches capacity } \\
\text { of beadline }\end{array}$ & $\begin{array}{l}\text { As high-affinity as } \\
\text { possible }\end{array}$ \\
\hline Starting point for & 170 beads & $34 \mu \mathrm{M}$ per mg of & $0.8 \mathrm{nM}$ & As high-affinity as \\
\hline
\end{tabular}




\begin{tabular}{|l|l|l|l|l|}
\hline $\begin{array}{l}0.1-10 \\
\text { molecules/s } \\
(30 \text { min assay } \\
\text { time) }\end{array}$ & $\begin{array}{l}\text { (in-droplet } \\
\text { dilution of factor } \\
50 \text { from stock) }\end{array}$ & beads & possible \\
\hline $\begin{array}{l}\text { Starting point for } \\
10-1000 \\
\text { molecules/s } \\
(0.5 \text { hour assay } \\
\text { time) }\end{array}$ & $\begin{array}{l}\text { 1,200 beads } \\
\text { (in-droplet } \\
\text { dilution of factor } \\
4 \text { from stock) }\end{array}$ & $\begin{array}{l}75 \mathrm{nM} \text { per } \\
\text { droplet }\end{array}$ & $\begin{array}{l}75 \mathrm{nM} \\
(30 \mathrm{nM} \text { for } \\
\text { antigen) }\end{array}$ & $\begin{array}{l}\text { As high-affinity as } \\
\text { possible }\end{array}$ \\
\hline
\end{tabular}

"The magnitude of the effect is indicated: +++, strong; ++, medium; +, weak; -, no effect.

\section{- END OF BOX 1 -}

\section{Box 2 Extraction of parameters}

1422

1423

1424

1425

1426

Limit of detection: This requires a calibration curve, a negative sample (e.g. cells not producing the analyte, and a positive sample (e.g. cells producing the analyte).

First, you will have to define a limit of detection (LOD) for the extracted secretion rate. Below this value, you will not be able to determine whether a cell secretes the analyte. To set-up the LOD, we recommend that you have a calibration curve, a negative sample as well as a sample (such as a cell line) with positive events. Use the data from the calibration curve to set various thresholds, and use them on the negative and positive samples to quantify the number of false-positives and negatives given a certain threshold. As a starting point, we use the definition of the limit of detection (LOD) by Armbuster and Pry ${ }^{86}$ that states:

$$
\text { Limit of detection }(L O D)=\overline{x_{\text {blank }}}+1.645 * \sigma_{\text {blank }}+1.645 * \sigma_{\text {low }}
$$

where $x_{\text {blank }}$ is the mean fluorescence relocation in a negative sample, $\sigma_{\text {blank }}$ its standard deviation and $\sigma_{\text {low }}$ the standard deviation of a sample with low concentration. If this threshold is too low, you will include mostly false-positives events (visible by an increased number of events in the negative sample), whereas a too high threshold increases false-negatives (a decreased number of events in the positive sample). If the analytical resolution is too low, set-up the assay anew with different antibodies or concentration ranges (Box 1) and repeat the experiments.

CRITICAL: A good labelling and high signals will decrease the limit of detection and decrease the frequency of false-positives and negatives.

Number of cells: Droplets with living cells are automatically detected in the analytical pathway. It is important to have a low mean number of cells per droplet $(\lambda<0.2)$ and the absence of cell clusters. 
Secretion rates: This requires a calibration curve and data measured over time.

1443 Your calibration curve will consist of an increasing phase of fluorescence relocation, a plateau and an ensuing decreasing phase, due the Hook effect (see Fig. 3b, e).Present in one-step immunoassays, the Hook effect leads to a decrease in signal at very high analyte concentrations. In our case, at analyte concentrations higher than beadline capacity, the non-bound analyte competes with the bound analyte for the detection reagent; and the measured fluorescence relocation decreases.

1448

1449

1450

1451

1452

1453

1454

1455

1456

1457

1458

1459

1460

1461

1462

1463

1464

1465

1466

1467

1468

1469

1470

1471

1472

1473 Therefore, take care to use only the increasing phase for calculations of secretion rates in the cell measurements. Use the fitting parameters from the calibration curve to calculate the measured indroplet fluorescence relocation into concentration. The secretion rate is then simply calculated by the change of concentration over time. For each droplet followed over time, we can therefore define:

1. Secretion rate $\left[\frac{\text { molecules }}{s}\right]=\left(\frac{1}{n-1}\left(\sum_{1}^{n-1} \frac{c_{i+1}-c_{i}}{\Delta t}\right)\right) * N_{A} * V$

with $\mathrm{n}$ as the number of time points, $\mathrm{c}$ as the concentration present in the droplet at each time (in $\mathrm{pM}$; according to the calibration curve), $\Delta \mathrm{t}$ as the time difference between two measurement points, $\mathrm{N}_{\mathrm{A}}$ as the Avogadro constant and $\mathrm{V}$ as the volume of the droplet (in $\mathrm{pL}$ ).

Extraction of affinity (IgG assay): Additionally, when a fluorescent variant of the antigen of interest is introduced into the assay, affinity of the secreted antibodies can be assayed (for more information, see reference $\left.{ }^{38}\right)$. The ratio of relocated antigen fluorescence onto the beadline and free antigen within the droplet can be used to calculate the strength of the interaction $\left(K_{D}\right)$ once the concentration of antibody is known. This concentration is accessible using calibration curves (see Secretion rate above). If the secreted IgG recognizes the antigen, the ratio of fluorescent antigen bound to $\lg G$ on the beadline and mean fluorescence within the droplet can be used to calculate the strength of the interaction $\left(K_{\mathrm{D}}\right)$. The $K_{\mathrm{D}}$ is determined from the slope of the line defined by plotting the relocation of fluorescent anti-IgG $F\left(a b^{\prime}\right) 2$ (concentration dependent) against the relocation of fluorescent antigen to the beadline at different concentrations of IgG below the maximum capacity of the beadline ( $\leq 50 \mathrm{nM}$, concentration and affinity dependent).

\section{[PRODUCTION : Please place Figure for Box 2 here].}

Measurement of murine IgG affinity. Relocation of fluorescent antigen and fluorescent anti-IgG detection antibody are determined by dividing the fluorescence intensity measured on the magnetic beadline $\left(I_{B}\right)$ by the background fluorescence of the droplet $\left(I_{D}\right)$. To calculate $K_{D}$, antigen relocation $\left(I_{B} / I_{D}\right.$ antigen $)$ is plotted against anti-IgG detection antibody relocation $\left(I_{B} / I_{D}\right.$ anti-lgG $)$. The slope of this plot increases with increasing affinity, i.e. decreasing $K_{\mathrm{D}}$. The use of several antibodies with 

different, but known affinities (measured, for example, using surface plasmon resonance) allows calibration of the slope to determine $K_{\mathrm{D}}$.

Slopes of several antibodies with known affinity against the antigen are needed to calibrate the assay. We determined the slopes for a panel of 7 purified anti-TT IgGs with affinities ranging from 300 to $0.02 \mathrm{nM}$ in our initial study ${ }^{38}$, and have since reproduced this curve using a variety of different antigens. If the antigen is multimeric, or epitopes are present more than once, an apparent dissociation constant will be measured instead of $K_{\mathrm{D}}$.

Be aware that the slope for different isotypes (e.g. for $\lg G 1$ and $\operatorname{IgG2}$ ) will need different calibration curves due to their difference in fluorescence relocation ${ }^{38}$. If the slope is below 0.03 ; no affinity can be detected. If the slope is above $1 ; K_{\mathrm{D}}$ is at or below $0.1 \mathrm{nM}$ but cannot be resolved anymore. In order to validate the antigen and antibodies, and to make sure that the calibration curve can be used for the system of interest, we assay 2-3 antibodies with known but different affinity; and use the slope to calculate the $K_{\mathrm{D}}$. The $K_{\mathrm{D}}$ should be compared with the $K_{\mathrm{D}}$ measured using an independent method, such as Surface Plasmon Resonance.

\section{- END OF BOX 2 -}

\section{Box 3 Distribution of cells and nanoparticles per droplet}

Cells. In the absence of cell clusters (i.e. the cells are well individualized and suspended), the cellular loading in this protocol follows a Poisson distribution, which is a special case of the binomial distribution. The mean number of cells per droplet, $\lambda$, is determined by the number of cells in the initial solution and the volume of an individual droplet (see the table below, $50 \mathrm{pL}$ droplets). While a higher $\lambda$ will increase the throughput and might be advantageous to increase the number of low frequency events, lower $\lambda$ is preferable for single-cell measurements. Higher $\lambda$ will increase the frequency of droplets containing multiple cells, and data analysis needs to be adapted to cope with these events. We usually aim for a $\lambda$ of around $0.2-0.3$, which is a compromise between maximizing the frequency of droplets with one cell and minimizing the frequency of with multiple cells (see the table below). We recommend validating the $\lambda$ for each experiment by counting the number of cells in a subset of droplets (e.g. 50 droplets) since it will also be needed to calculate the total number of cells, and the frequency of positive events (see Box 2).

\begin{tabular}{|l|l|l|l|l|}
\hline $\begin{array}{l}\text { Cells per } \mathrm{ml} \\
{[\mathrm{Mio} / \mathrm{ml}]}\end{array}$ & $\lambda$ & Empty droplet & $\begin{array}{l}\text { Droplets with a } \\
\text { single cell }\end{array}$ & $\begin{array}{l}\text { Droplets with } \\
\text { multiple cells }\end{array}$ \\
\hline
\end{tabular}




\begin{tabular}{|l|l|l|l|l|}
\hline 5 & 0.1 & $90 \%$ & $9.5 \%$ & $0.5 \%$ \\
\hline 10 & 0.2 & $78 \%$ & $19 \%$ & $3 \%$ \\
\hline 20 & 0.4 & $67 \%$ & $27 \%$ & $6 \%$ \\
\hline
\end{tabular}

1504

1505

1506

1507

1508

1509

1510

1511

1512

1513

1514

1515

1516

1517

1518

1519

1520

1521

1522

1523

1524

1525

1526

1527

1528

1529

1530

1531

1532

1533

Nanoparticles. An advantage of the protocol described here is the co-encapsulation of single cells with multiple nanoparticles instead of the co-encapsulation of a single cell and a single microparticle ${ }^{35,36}$. With a homogenous suspension of nanoparticles and a mean, $\lambda$, of hundreds to thousands of nanoparticles per droplet, the distribution is binomial. For the two conditions presented here (170 and 1,200 nanoparticles per droplet), the standard deviation is 7 and 17, respectively, and the coefficient of variance (CV) below 0.05 . Therefore, every droplet contains approximately the same number of nanoparticles and the low CV assures that drop-to-drop variation has a minimal impact on the results. If droplets with no beads are present during analysis, these likely stem from errors in the flow ratios during encapsulation, due, for example, to the presence of clusters of beads or cells, dust in the microfluidic chips or operating errors.

\section{- END OF BOX 3 -}

BOX 4. Detection of protein of interest using a microtiter plate (bulk) assay. TIMING $3 \boldsymbol{h}$ As an alternative to the droplet-based quality control assays of the functionalized nanoparticles, one can also perform a fluorescent-based immune-sandwich assay in microtiter plates. It should be noted that bulk assays use more reagents and a calibration curve can also be performed directly within droplets to allow for the quantitative measurement of secretion rates (Box 2, Fig. 3b and e).

\section{Procedure}

1. Prepare a serial dilution of recombinant protein of interest (typically in the range 0-100 nM) in PBS containing 1\% (wt/vol) BSA in a 96-well microtiter microplate. Final volumes should be $90 \mu$ l each.

2. Add $10 \mu \mathrm{l}$ of beads to each well containing the protein of interest, and then mix well by pipetting.

3. Incubate, shaking at $700 \mathrm{rpm}$, for 1 hour at room temperature.

4. Place the microtiter plate on a magnet holder for about 1 minute at room temperature.

5. Carefully discard the supernatant. Do not disturb the bead pellet.

6. Add $100 \mu$ l of PBS buffer to beads.

7. Remove the microtiter plate from the magnet holder and mix well by vortexing.

8. Repeat steps iv-vii once. 
1550

1551

1552

1553

1554

1555

1556

1557

1558

1559

1560

1561

1562

1563

1564

1565

1566

9. Collect the beads, carefully discard the supernatant then add $100 \mu \mathrm{l}$ of solution containing $0.8 \mu \mathrm{g} / \mathrm{ml}$ of fluorescent-labeled detection antibody to each well.

10. Incubate, shaking at $700 \mathrm{rpm}$, for 1 hour at room temperature.

11. Place the microtiter plate on a magnet holder for about 1 minute at room temperature.

12. Carefully discard the supernatant. Do not disturb the bead pellet.

13. Add $100 \mu$ l of PBS buffer to beads.

14. Remove the microtiter plate from the magnet holder and mix well by vortexing.

15. Repeat steps xi-xiv once.

16. Pellet the beads using the magnet and carefully discard the supernatant. Re-suspend the beads directly in $50 \mu \mathrm{L}$ PBS, mix gently by pipetting.

17. Transfer the samples to a black 96-well microtiter microplate and measure fluorescence at the wavelength optimal for the fluorophore on the detection antibody using the microplate reader.

18. Plot the curve of fluorescence intensity against the concentration of added protein of interest.

? TROUBLESHOOTING

- End of BOX 4-

\section{Acknowledgments}

We would like to acknowledge the support of the REALISM study group: HCL: André BOIBIEUX, Julien DAVIDSON, Laure FAYOLLE-PIVOT, Julie GATEL, Charline GENIN, Arnaud GREGOIRE, Alain LEPAPE, Anne-Claire LUKASZEWICZ, Guillaume MARCOTTE, Marie MATRAY, Delphine MAUCORT-BOULCH, Nathalie PANEL, Thomas RIMMELE, Hélène VALLIN. bioMérieux: Sophie BLEIN, Karen BRENGELPESCE, Elisabeth CERRATO, Valérie CHEYNET, Emmanuelle GALLET-GORIUS, Audrey GUICHARD, Camille JOURDAN, Natacha KOENIG, François MALLET, Boris MEUNIER, Marine MOMMERT, Guy ORIOL, Claire SCHREVEL, Olivier TABONE, Javier YUGUEROS MARCOS. BIOASTER: Jérémie BECKER, Frédéric BEQUET, Florian BRAJON, Bertrand CANARD, Muriel COLLUS, Nathalie GARCON, Irène GORSE, Fabien LAVOCAT, Karen LOUIS, Jeanne MORINIERE, Yoann MOUSCAZ, Laura NOAILLES, Magali PERRET, Frédéric REYNIER, Cindy RIFFAUD, Mary-Luz ROL, Nicolas SAPAY. SANOFI: Christophe CARRE, Aymeric DE MONFORT, Karine FLORIN, Laurent FRAISSE, Isabelle FUGIER, Maïna L'AZOU, Sandrine PAYRARD, Annick PELERAUX, Laurence QUEMENEUR. ESPCI: Stephanie TOETSCH. GSK: Teri 

RAYCHAUDHURI, Rob SMYLIE, Lionel TAN, Craig TIPPLE.

This research project has received funding from the French Government through the "Investissement d'Avenir" program (grant nANR-10-AIRT-03) and from bioMérieux. E.K. acknowledges generous funding from the 'The Branco Weiss Fellowship - Society in Science' and received funding from the European Research Council (ERC) under the European Union's Horizon 2020 research and innovation programme (Grant agreement No. 80336). This work also received the support of "Institut PierreGilles de Gennes" (laboratoire d'excellence, "Investissements d'Avenir" program ANR-10-IDEX-000102 PSL, ANR-10- EQPX-34 and ANR-10-LABX-31). This work was also supported by BPIFrance under the frame "Programme d'Investissements d'Avenir" (CELLIGO Project).

1577

The authors thank the healthy donors and the septic patients who volunteered to donate peripheral blood for these experiments. We would like to thank Marie-Noelle Unheheuer, Hélène Laude and Blanca Liliana Perlaza for access to BioResources platform (ICAReB). We thank Frédéric Pène who collected clinical samples from septic shock patients at the medical intensive care unit of Cochin

1581 hospital (CPP17-053a / 2017-A01134-49). We thank Fabrice Porcheray for critical reading of the manuscript.

1583

1584

1585

1586

1587

We would like to further acknowledge the help of Dr. P. Canales Herrerias and Dr. P. Bruhns for their helpful discussion and supervision of the immunization of mice.

The original data used in this publication are made available in a curated data archive at ETH Zürich (https://www.research-collection.ethz.ch) under the DOI 330317.

\section{Competing interests}

Some of the authors (Jean Baudry, Jérôme Bibette, Andrew Griffiths, Yacine Bounab, Christophe Védrine) are inventors on patent applications based on certain ideas described in this manuscript and may receive financial compensation via their employer's rewards to inventors scheme.

\section{Author Contributions}

Y.B., K.E., M.R. and N.A. performed and optimized the experiments described in this protocol, S.D. and G.C. provided the respective Matlab Scripts for data analysis, C.C and T.T. provided the statistical tools. M.M. optimized the boronic acid nanobead functionalization protocol. CV and J.Ba. managed 
1597 the optical bench set-up. J-F.L supplied the septic clinical samples. K.E, J.Bi., J.Ba and A.D.G. 1598 developed the DropMap technology ${ }^{38}$ and contributed to the early stage definition of the new 1599 technology. Y.B. and C.V. extended DropMap technology to measure low cytokine secretion profile

1600

1601

1602

1603

1604

1605

1606

1607

1608

1609

1610

1611

1612

1613

1614

1615

1616

1617

1618

1619

1620 and to overcome limitations of cell endocytic activity. G.M., A.P., J.T. designed and setup the clinical study involving sepsis and matched-control patients. A.T., C.G., P.L., V.M., F.V., P.C., I.G. supervised the work, participated to the design of technical experiments and of the clinical study and actively contributed in writing different sections of the manuscript. Y.B., S.D. and C.V. analyzed the data for the sepsis application, and Y.B., K.E., J.Ba., A.D.G., C.V. wrote the manuscript. All authors edited and proof-read the paper.

\section{Code availability statement}

DropMap Matlab script is available from GitHub repository, https://github.com/LCMDESPCl/dropmap-analyzer. Matlab scripts illustrating the main functions performed by the DropCell.exe Matlab application are available from GitHub repository, https://github.com/bioaster/dropcell.git. Installation file for DropCell.exe Matlab application as well as an image data set that support/illustrate the findings of this study are available in figshare repository, with the identifiers https://doi.org/10.6084/m9.figshare.11336663.v1 and https://figshare.com/articles/dropcell_image_data_set/11342426, respectively.

\section{Data availability statement}

The datasets generated during and/or analysed during the current study are not publicly available due to confidentiality and contractual obligations towards industrial partners of the project in which the data have been generated, but are available from the corresponding author on reasonable request. 


\section{References}

1622

1623

1624

1625

1626

1627

1628

1629

1630

1631

1632

1633

1634

1635

1636

1637

1638

1639

1640

1641

1642

1643

1644

1645

1646

1647

1648

1649

1650

1651

1652

1653

1654

1655

1656

1657

1658

1659

1660

1661

1662

1663

1664

1665

1666

1667

1668

1669

1670

1. Lawson, D.A., Kessenbrock, K., Davis, R.T., Pervolarakis, N. \& Werb, Z. Tumour heterogeneity and metastasis at single-cell resolution. Nat Cell Biol 20, 1349-1360 (2018).

2. Potter, S.S. Single-cell RNA sequencing for the study of development, physiology and disease. Nat Rev Nephrol 14, 479-492 (2018).

3. Stuart, T. \& Satija, R. Integrative single-cell analysis. Nat Rev Genet 20, 257-272 (2019).

4. Svensson, V., Vento-Tormo, R. \& Teichmann, S.A. Exponential scaling of single-cell RNA-seq in the past decade. Nat Protoc 13, 599-604 (2018).

5. Zhang, X. et al. Comparative Analysis of Droplet-Based Ultra-High- Throughput Single-Cell RNA-Seq Systems. Molecular Cell, 1-19 (2018).

6. Battle, A. et al. Genomic variation. Impact of regulatory variation from RNA to protein. Science (New York, N.Y.) 347, 664-667 (2015).

7. Peterson, V.M. et al. Multiplexed quantification of proteins and transcripts in single cells. Nature Biotechnology 35, 936-939 (2017).

8. Shapiro, H.M. Practical Flow Cytometry. (Wiley-Liss, New York; 2003).

9. Bendall, S.C. et al. Single-cell mass cytometry of differential immune and drug responses across a human hematopoietic continuum. Science (New York, NY) 332, 687-696 (2011).

10. Becattini, S. et al. Functional heterogeneity of human memory CD4(+) T cell clones primed by pathogens or vaccines. Science (New York, N.Y.) 347, 400-406 (2015).

11. Betts, M.R. et al. Sensitive and viable identification of antigen-specific CD8+ T cells by a flow cytometric assay for degranulation. J Immunol Methods 281, 65-78 (2003).

12. Han, G., Spitzer, M.H., Bendall, S.C., Fantl, W.J. \& Nolan, G.P. Metal-isotope-tagged monoclonal antibodies for high-dimensional mass cytometry. Nature protocols 13, $2121-$ 2148 (2018).

13. Korin, B., Dubovik, T. \& Rolls, A. Mass cytometry analysis of immune cells in the brain. Nature protocols 13, 377-391 (2018).

14. Stoeckius, M. et al. Simultaneous epitope and transcriptome measurement in single cells. Nature methods 14, 865-868 (2017).

15. Shahi, P., Kim, S.C., Haliburton, J.R., Gartner, Z.J. \& Abate, A.R. Abseq: Ultrahigh-throughput single cell protein profiling with droplet microfluidic barcoding. Scientific reports 7, 44447 (2017).

16. Czerkinsky, C.C., Nilsson, L.A., Nygren, H., Ouchterlony, O. \& Tarkowski, A. A solid-phase enzyme-linked immunospot (ELISPOT) assay for enumeration of specific antibody-secreting cells. Journal of immunological methods 65, 109-121 (1983).

17. Kouwenhoven, M. et al. Enzyme-linked immunospot assays provide a sensitive tool for detection of cytokine secretion by monocytes. Clin Diagn Lab Immunol 8, 1248-1257 (2001).

18. Schultes, B.C. \& Whiteside, T.L. Monitoring of immune responses to CA125 with an IFNgamma ELISPOT assay. J Immunol Methods 279, 1-15 (2003).

19. Mogensen, T.H. Pathogen recognition and inflammatory signaling in innate immune defenses. Clinical microbiology reviews 22, 240-273, Table of Contents (2009).

20. Garcia-Cordero, J.L., Nembrini, C., Stano, A., Hubbell, J.A. \& Maerkl, S.J. A high-throughput nanoimmunoassay chip applied to large-scale vaccine adjuvant screening. Integrative biology : quantitative biosciences from nano to macro 5, 650-658 (2013).

21. Han, Q. et al. Polyfunctional responses by human T cells result from sequential release of cytokines. Proceedings of the National Academy of Sciences of the United States of America 109, 1607-1612 (2012).

22. Han, Q., Bradshaw, E.M., Nilsson, B., Hafler, D.A. \& Love, J.C. Multidimensional analysis of the frequencies and rates of cytokine secretion from single cells by quantitative microengraving. Lab on a chip 10, 1391-1400 (2010).

23. Shirasaki, Y. et al. Real-time single-cell imaging of protein secretion. Sci Rep 4, 4736 (2014). 
24. Son, K.J. et al. Microfluidic compartments with sensing microbeads for dynamic monitoring of cytokine and exosome release from single cells. The Analyst 141, 679-688 (2016).

25. Varadarajan, $\mathrm{N}$. et al. A high-throughput single-cell analysis of human CD8(+) T cell functions reveals discordance for cytokine secretion and cytolysis. The Journal of clinical investigation 121, 4322-4331 (2011).

26. Xue, Q. et al. Single-cell multiplexed cytokine profiling of CD19 CAR-T cells reveals a diverse landscape of polyfunctional antigen-specific response. Journal for immunotherapy of cancer 5, 85 (2017).

27. Xue, Q. et al. Analysis of single-cell cytokine secretion reveals a role for paracrine signaling in coordinating macrophage responses to TLR4 stimulation. Science signaling 8, ra59 (2015).

28. Yamanaka, Y.J. et al. Cellular barcodes for efficiently profiling single-cell secretory responses by microengraving. Analytical chemistry 84, 10531-10536 (2012).

29. Seah, Y.F.S., Hu, H. \& Merten, C.A. Microfluidic single-cell technology in immunology and antibody screening. Molecular aspects of medicine 59, 47-61 (2018).

30. Love, J., Ronan, J., Grotenbreg, G., Van Der Veen, A. \& Ploegh, H. A microengraving method for rapid selection of single cells producing antigen-specific antibodies. Nat Biotechnol 24, 703-707 (2006).

31. Jin, A. et al. Rapid isolation of antigen-specific antibody-secreting cells using a chip-based immunospot array. Nature protocols 6, 668-676 (2011).

32. Köster, S. et al. Drop-based microfluidic devices for encapsulation of single cells. Lab on $a$ chip 8, 1110-1115 (2008).

33. Clausell-Tormos, J. et al. Droplet-based microfluidic platforms for the encapsulation and screening of Mammalian cells and multicellular organisms. Chemistry \&amp; biology 15, 427437 (2008).

34. El Debs, B., Utharala, R., Balyasnikova, I.V., Griffiths, A.D. \& Merten, C.A. Functional singlecell hybridoma screening using droplet-based microfluidics. Proceedings of the National Academy of Sciences 109, 11570-11575 (2012).

35. Mazutis, L. et al. Single-cell analysis and sorting using droplet-based microfluidics. Nature protocols 8, 870-891 (2013).

36. Shembekar, N., Hu, H., Eustace, D. \& Merten, C.A. Single-Cell Droplet Microfluidic Screening for Antibodies Specifically Binding to Target Cells. CellReports 22, 2206-2215 (2018).

37. Chokkalingam, V. et al. Probing cellular heterogeneity in cytokine-secreting immune cells using droplet-based microfluidics. Lab Chip 13, 4740-4744 (2013).

38. Eyer, K. et al. Single-cell deep phenotyping of IgG-secreting cells for high-resolution immune monitoring. Nat Biotechnol 35, 977-982 (2017).

39. Jorgolli, M. et al. Nanoscale integration of single cell biologics discovery processes using optofluidic manipulation and monitoring. Biotechnol Bioeng 116, 2393-2411 (2019).

40. Mocciaro, A. et al. Light-activated cell identification and sorting (LACIS) for selection of edited clones on a nanofluidic device. Commun Biol 1, 41 (2018).

41. Winters, A. et al. Rapid single B cell antibody discovery using nanopens and structured light. mAbs 11, 1025-1035 (2019).

42. Konry, T., Dominguez-Villar, M., Baecher-Allan, C., Hafler, D.A. \& Yarmush, M.L. Dropletbased microfluidic platforms for single $\mathrm{T}$ cell secretion analysis of IL-10 cytokine. Biosens Bioelectron 26, 2707-2710 (2011).

43. Qiu, L. et al. A membrane-anchored aptamer sensor for probing IFNgamma secretion by single cells. Chem Commun (Camb) 53, 8066-8069 (2017).

44. Segaliny, A.l. et al. Functional TCR T cell screening using single-cell droplet microfluidics. Lab on a chip 18, 3733-3749 (2018).

45. Gérard, A., Woolfe, A. \& Mottet, G., Reichen, M., Castrillon, C., Menrath, V., Ellouze, S., Poitou, A., Doineau, R., Briseno-Roa, L., Canales-Herrerias, P., Mary, P., Rose, G., Ortega, C., Delincé, M., Essono, S., Jia, B., lannascoli, B., Richard-LeGoff, O., Kumar, R., Stewart, S.N., Pousse, Y., Shen, B., Grosselin, K., Saudemont, B., Sautel-Caillé, A., Godina, A., McNamara, S., 
Eyer, K., Millot, G.A., Baudry, J., England, P., Nizak, C., Jensen, A., Griffiths, A.D., Bruhns, P., and Brenan. C. High-throughput single-cell activity-based screening and sequencing of antibodies using droplet microfluidics. . Nature Biotechnology (In press).

46. Duffy, D.C., McDonald, J.C., Schueller, O.J.A. \& G.M., W. Rapid prototyping of microfluidic systems in poly(dimethylsiloxane). Analytical chemistry 70, 4974-4984 (1998).

47. Anna, S.L., Bontoux, N. \& Stone, H.A. Formation of dispersions using "flow focusing" in microchannels. Appl Phys Lett 82, 364-366 (2003).

48. Akhtar, M., Driesche, S. \& Vellekoop, M.J. On-chip storage of droplets in parylene-AF4 coated PDMS channels. (2014).

49. Di Carlo, D., Aghdam, N. \& Lee, L.P. Single-cell enzyme concentrations, kinetics, and inhibition analysis using high-density hydrodynamic cell isolation arrays. Analytical chemistry 78, 49254930 (2006).

50. Jin, S.H., Jeong, H.H., Lee, B., Lee, S.S. \& Lee, C.S. A programmable microfluidic static droplet array for droplet generation, transportation, fusion, storage, and retrieval. Lab on a chip 15, 3677-3686 (2015).

51. Liu, C., Liu, J., Gao, D., Ding, M. \& Lin, J.M. Fabrication of microwell arrays based on twodimensional ordered polystyrene microspheres for high-throughput single-cell analysis. Analytical chemistry 82, 9418-9424 (2010).

52. Ochsner, M. et al. Micro-well arrays for 3D shape control and high resolution analysis of single cells. Lab on a chip 7, 1074-1077 (2007).

53. Schmitz, C.H., Rowat, A.C., Koster, S. \& Weitz, D.A. Dropspots: a picoliter array in a microfluidic device. Lab on a chip 9, 44-49 (2009).

54. Duval, F., van Beek, T.A. \& Zuilhof, H. Key steps towards the oriented immobilization of antibodies using boronic acids. The Analyst 140, 6467-6472 (2015).

55. Kumar, S., Aaron, J. \& Sokolov, K. Directional conjugation of antibodies to nanoparticles for synthesis of multiplexed optical contrast agents with both delivery and targeting moieties. Nature protocols 3, 314-320 (2008).

56. Saha, B., Evers, T.H. \& Prins, M.W. How antibody surface coverage on nanoparticles determines the activity and kinetics of antigen capturing for biosensing. Anal Chem 86, 81588166 (2014).

57. Saha, B., Songe, P., Evers, T.H. \& Prins, M.W.J. The influence of covalent immobilization conditions on antibody accessibility on nanoparticles. The Analyst 142, 4247-4256 (2017).

58. Sivaram, A.J., Wardiana, A., Howard, C.B., Mahler, S.M. \& Thurecht, K.J. Recent Advances in the Generation of Antibody-Nanomaterial Conjugates. Advanced healthcare materials 7 (2018).

59. Welch, N.G., Scoble, J.A., Muir, B.W. \& Pigram, P.J. Orientation and characterization of immobilized antibodies for improved immunoassays (Review). Biointerphases 12, 02d301 (2017).

60. Dhadge, V.L., Hussain, A., Azevedo, A.M., Aires-Barros, R. \& Roque, A.C. Boronic acidmodified magnetic materials for antibody purification. Journal of the Royal Society, Interface 11, 20130875 (2014).

61. Lin, P.C. et al. Fabrication of oriented antibody-conjugated magnetic nanoprobes and their immunoaffinity application. Anal Chem 81, 8774-8782 (2009).

62. Wang, X., Xia, N. \& Liu, L. Boronic Acid-based approach for separation and immobilization of glycoproteins and its application in sensing. International journal of molecular sciences 14, 20890-20912 (2013).

63. Wagner, O. et al. Biocompatible fluorinated polyglycerols for droplet microfluidics as an alternative to PEG-based copolymer surfactants. Lab on a chip 16, 65-69 (2016).

64. Williamson, J.D. \& Cox, P. Use of a new buffer in the culture of animal cells. The Journal of general virology 2, 309-312 (1968).

65. Lowe, K.C. Perfluorochemical respiratory gas carriers: benefits to cell culture systems. Journal of Fluorine Chemistry 118, 19-26 (2002). 
66. Holtze, C. et al. Biocompatible surfactants for water-in-fluorocarbon emulsions. Lab on a chip 8, 1632-1639 (2008).

67. Mazutis, L. \& Griffiths, A.D. Selective droplet coalescence using microfluidic systems. Lab on a chip 12, 1800-1806 (2012).

68. Scott, R.L. The solubility of fluorocarbons. J Am Chem Soc 70, 4090-4093 (1948).

69. Simons, J.H. \& Linevsky, M.J. The Solubility of Organic Solids in Fluorocarbon Derivatives. Journal of the American Chemical Society 74, 4750-4751 (1952).

70. Qin, D., Xia, Y. \& Whitesides, G.M. Soft lithography for micro- and nanoscale patterning. Nature protocols 5, 491-502 (2010).

71. Heo, M. et al. Deep-phenotypic characterization of the immunization induced anti-bacterial immunoglobulin-G repertoire. (submitted).

72. Eyer, K. et al. Recall analysis as an integrative study tool of immunizations. (submitted).

73. Raphael, I., Nalawade, S., Eagar, T.N. \& Forsthuber, T.G. T cell subsets and their signature cytokines in autoimmune and inflammatory diseases. Cytokine 74, 5-17 (2015).

74. Tanaka, A. \& Sakaguchi, S. Regulatory T cells in cancer immunotherapy. Cell Res 27, 109-118 (2017).

75. Kang, S., Brown, H.M. \& Hwang, S. Direct Antiviral Mechanisms of Interferon-Gamma. Immune Netw 18, e33 (2018).

76. Mosmann, T.R., Cherwinski, H., Bond, M.W., Giedlin, M.A. \& Coffman, R.L. Two types of murine helper $T$ cell clone. I. Definition according to profiles of lymphokine activities and secreted proteins. J Immunol 136, 2348-2357 (1986).

77. Wheelock, E.F. Interferon-Like Virus-Inhibitor Induced in Human Leukocytes by Phytohemagglutinin. Science (New York, N.Y.) 149, 310-311 (1965).

78. DuPage, M. \& Bluestone, J.A. Harnessing the plasticity of $\mathrm{CD} 4(+) \mathrm{T}$ cells to treat immunemediated disease. Nat Rev Immunol 16, 149-163 (2016).

79. Cecconi, M., Evans, L., Levy, M. \& Rhodes, A. Sepsis and septic shock. Lancet 392, 75-87 (2018).

80. Gyawali, B., Ramakrishna, K. \& Dhamoon, A.S. Sepsis: The evolution in definition, pathophysiology, and management. SAGE Open Med 7, 2050312119835043 (2019).

81. Monneret, G. et al. Novel Approach in Monocyte Intracellular TNF Measurement: Application to Sepsis-Induced Immune Alterations. Shock (Augusta, Ga.) 47, 318-322 (2017).

82. Shalova, I.N. et al. Human monocytes undergo functional re-programming during sepsis mediated by hypoxia-inducible factor-1alpha. Immunity 42, 484-498 (2015).

83. Kumar, P., Pai, K., Pandey, H.P. \& Sundar, S. Study on pinocytosis by monocytes from visceral leishmaniasis patients, Vol. 83. (2002).

84. Luciani, N., Gazeau, F. \& Wilhelm, C. Reactivity of the monocyte/macrophage system to superparamagnetic anionic nanoparticles. Journal of Materials Chemistry 19, 6373-6380 (2009).

85. Robert, D. et al. Cell sorting by endocytotic capacity in a microfluidic magnetophoresis device. Lab on a chip 11, 1902-1910 (2011).

86. Armbruster, D.A. \& Pry, T. Limit of blank, limit of detection and limit of quantitation. Clin Biochem Rev 29 Suppl 1, S49-52 (2008).

\section{FIGURE LEGENDS}

Figure 1. Single cell secretion assay in microfluidic droplets. (a) Co-encapsulation of cells and assay reagents into picoliter droplets. Red arrows show individual cells in droplets. Scale bars $50 \mu \mathrm{m}(\mathrm{b}, \mathrm{c})$ Principle of the single-cell secretion assay in droplets. The bioassay comprises magnetic nanoparticles 
1822 (300 nm diameter) functionalized with capture antibodies, and fluorescently-labeled detection 1823 antibodies. In the absence of secreted analyte (b), no binding occurs on the magnetic beadline and 1824 the fluorescent signal remains homogenous within the droplet. In the presence of secreted analyte 1825 (c), antibody-coated beads capture the secreted analyte and the fluorescent signal becomes 1826 relocalized to the beadline, due to the fluorescently-labelled detection antibody binding the captured 1827 analyte. Black arrows (B->) below the droplet indicate the direction of the magnetic field that induces beadline formation in the droplets. Both scale bars $25 \mu \mathrm{m}$. (d) A brightfield image of beadlines and monocytes in a compact array of $50 \mathrm{pL}$ droplets. Scale bar $50 \mu \mathrm{m}$. (e) Complete chip design used to co-encapsulate cells and reagents. Scale bar $750 \mu \mathrm{m}$.

1831

1832

Figure 2. Fabrication of the microfluidic glass chamber using double-sided adhesive tape. (a) Dimensions of the lower and upper glass slides enclosing the chamber. The upper slide contains two $1 \mathrm{~mm}$ wide holes. Droplets are injected through one hole (the other one acting as a vent). (b) Dimensions of the adhesive tape and pattern of the chamber. (c) Key steps for droplet chamber fabrication (step numbers refer to the steps described in the Procedure section of the manuscript). (d) Brightfield images of the glass/tap composite: Saffman-Taylor fingers are formed at room temperature (RT); they are not formed after a $90^{\circ} \mathrm{C}$ incubation (28(A).vi) . (e-f) Device composition: two glass slides (at bottom and top) sealed with the double-sided adhesive tape, two inlet/outlet nanoports (in the top glass slide, sealed with two caps), and a magnet glued to the bottom glass slide (alternative chamber fabrication 1).

Figure 3. Characterization of functionalized nanoparticles in droplets. (a) Schematic representation of nanoparticle coating for TNF- $\alpha$ detection. The bioassay comprises paramagnetic nanobeads functionalized with anti-TNF- $\alpha$ antibodies using boronic acid coupling to glycosyl groups. (b) Detection of human recombinant TNF- $\alpha$ in $50 \mathrm{pL}$ droplets. The relocation of the fluorescently-labeled detection antibodies in the presence of different concentrations of TNF- $\alpha$. The signal was determined by dividing the fluorescence intensity measured on the magnetic beadline $\left(I_{B}\right)$ by the background fluorescence of the droplet $\left(I_{D}\right)$. Top left, brightfield image. Bottom left, fluorescent image. Right, 1850 signal $\left(\mathrm{I}_{\mathrm{B}} / \mathrm{I}_{\mathrm{D}}\right)$ as a function of TNF- $\alpha$ concentration. (c) Time courses of TNF- $\alpha$ secretion by individual monocytes. Each curve represents the kinetic signal of a single cell. Top left, brightfield image. Bottom left, fluorescent image. Right, signal $\left(I_{B} / I_{D}\right)$ as a function of time, each curve represents the signal of a single cell. Black lines indicate the relocation within droplets with non-secreting cells. (d) Schematic representation of nanoparticle coating for IgG detection. The bioassay comprises paramagnetic nanobeads functionalized with anti-mouse kappa light chain $\mathrm{V}_{\mathrm{H}} \mathrm{H}$ that capture IgG onto 
the bead surface. (e) Detection of murine recombinant IgG1 (circles) and IgG2 (squares) in $50 \mathrm{pL}$ droplets. Top left, brightfield image. Bottom left, fluorescent image. Right, signal $\left(I_{B} / I_{D}\right)$ as a function of IgG concentration (IgG1 detection reagent, red lines; IgG2 detection reagent, green lines). (f) Time course analyses of IgG secretion of individual B cells. Top left, brightfield image. Bottom left, fluorescent image. Right, signal $\left(I_{B} / I_{D}\right)$ as a function of time, each curve represents the mean signal of a single cell (IgG1, red lines; IgG2, green lines). Black lines indicate the relocation within droplets with non-secreting cells. All scale bars are $25 \mu \mathrm{m}$.

Figure 4. Analysis pipeline. (a) Acquisition of images of the monolayer of droplets, illustrated for a single field of view in 5 imaging channels. Measurements were repeated at regular time intervals. (b) Detection of droplet contours in the field, and of the intra-droplet beadline (bright-field image) (c). Tracking of droplets allows continued analysis in spite of potential small droplet movements (supplementary Fig. 3 and supplementary method 1). (d) Images illustrating multiplexed and dynamic analyses of single monocytes. The droplet sub-image is shown in the five different imaging channels. Bright-field is used to detect droplets and magnetic beadlines, a Cy3 cube (orange fluorescence) is used to detect the secreted TNF- $\alpha$ on the beadline, a Cy5 cube (far red fluorescence) is used to detect living cells, a GFP cube (far-red fluorescence) is used to detect dead cells, and a DAPI cube (blue violet conjugate fluorescence) is used to detect cells expressing the cell surface marker CD14. The CD14 positive monocytes remained alive over $180 \mathrm{~min}$ and TNF- $\alpha$ relocalization on the beadline is detected $60 \mathrm{~min}$ after stimulation in droplets at $37^{\circ} \mathrm{C}$. At $180 \mathrm{~min}$, the cell shows an apoptotic activity indicating the death of the cell. Live and dead monocytes were determined by staining with MitoView and NucView to measuring mitochondrial membrane potential and caspase-3 activity, respectively. Scale bar $50 \mu \mathrm{m}$.

Figure 5. Analysis of cytokine secretion from human single T cells. (a) Distribution of the frequencies of TNF- $\alpha$ (17 \pm , (b) IFN- $\gamma$, (c) IL-2 and (d) IL-4 secreting T cells (identified using a fluorescent FITCconjugated anti-CD3 antibody) in PMA/ionomycin stimulated human PBMCs (orange) and nonstimulated PBMCs (black). Panels a and b depict 4,515 cells for stimulated, and 7'525 cells for nonstimulated PBMCs. Panels $\mathrm{c}$ and d depict 8,640 and 8,606 individually assayed cells for stimulated and non-stimulated cells respectively. The data represents a single experiment. No or only little secretion was found in the population of CD3 negative cells. Gray bars represent the part of the distribution that could not be analyzed due to the LOD of the assays (see also Box 1 and 2).

Figure 6. Analysis of TNF- $\alpha$ secretion from human single monocytes of healthy donor and septic shock patient. (a) Distribution of the frequencies of TNF- $\alpha$ secreting monocytes upon LPS stimulation 
1891 of a healthy donor (black line, 3008 cells) and septic shock patient (orange line, 2473 cells). (b) 1892 Distribution of the frequencies of TNF- $\alpha$ secreting monocytes upon LPS stimulation (black line, 3008 1893 cells) and non-stimulated cells (dashed line, 1099 cells) of a healthy donor. Low secreting cells exhibit 1894 TNF- $\alpha$ secretion rate below 0.5 molecules per second. The data represents a single experiment. Gray bars ( $a$ and $b$ ) represent the part of the distribution that could not be analyzed due to the LOD (TNF$\alpha$ secretion rate below 0.5 molecules per second) of the assay (see also Box 1 and 2). (c) Percentage of low secreting monocytes of septic patients ( $N=3$ patients, black squares, $29 \pm 8 \%$, mean \pm standard deviation for the independent experiments) and healthy donors ( $N=3$ donors, black circles, $6 \pm 6 \%$, mean \pm standard deviation for the independent experiments). Error bars show standard deviation1900

\section{List of supplementary information}

1903 Supplementary Figure 1. Explanatory figure for steps 33-35 to assemble the tip connectors and the 1904 syringes for the aqueous phases.

1905 Supplementary Figure 2. Explanatory figure for step 40 to position the chamber on the microscope 1906 stage insert.

1907 Supplementary Figure 3. Explanatory figure describing the pipeline analysis of droplet detection and 1908 tracking.

1909 Supplementary Method 1. Pipeline analysis of droplet detection and tracking.

1910 Supplementary Data 1. Complete chip design (CAD file).

1911 Supplementary Data 2. Mask for the double-sided tape to prepare the observation chamber.

1912 Supplementary Data 3. Mask for laser ablation.

1913 Supplementary Data 4. Mask for the magnet holder. 
a $\stackrel{2.5 \mathrm{~cm}}{\longleftrightarrow}$ Steps $26-27 \quad$ b

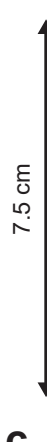

C
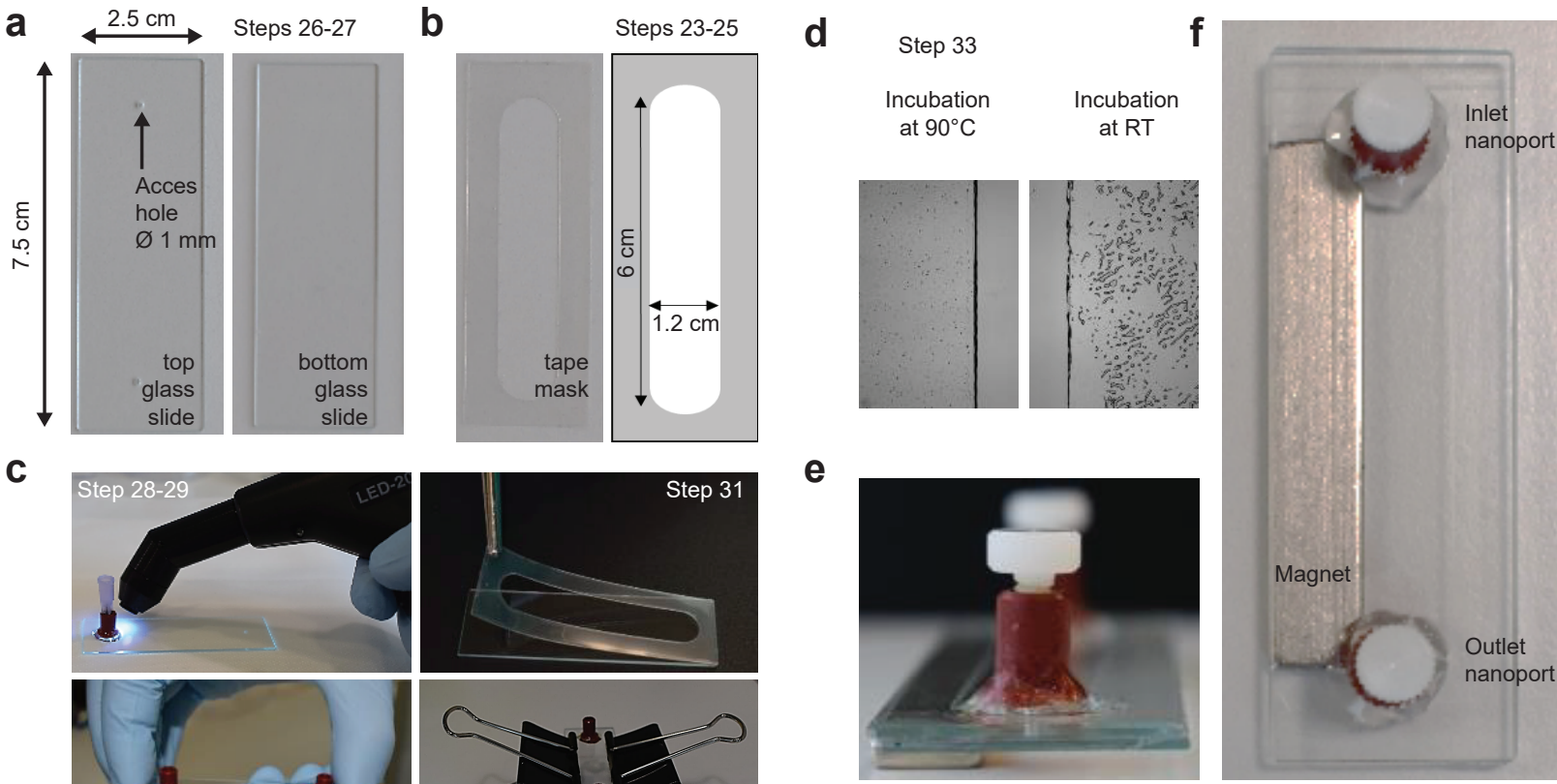

d

Step 33

Incubation

at $90^{\circ} \mathrm{C}$

Incubation

at RT

glass

slide

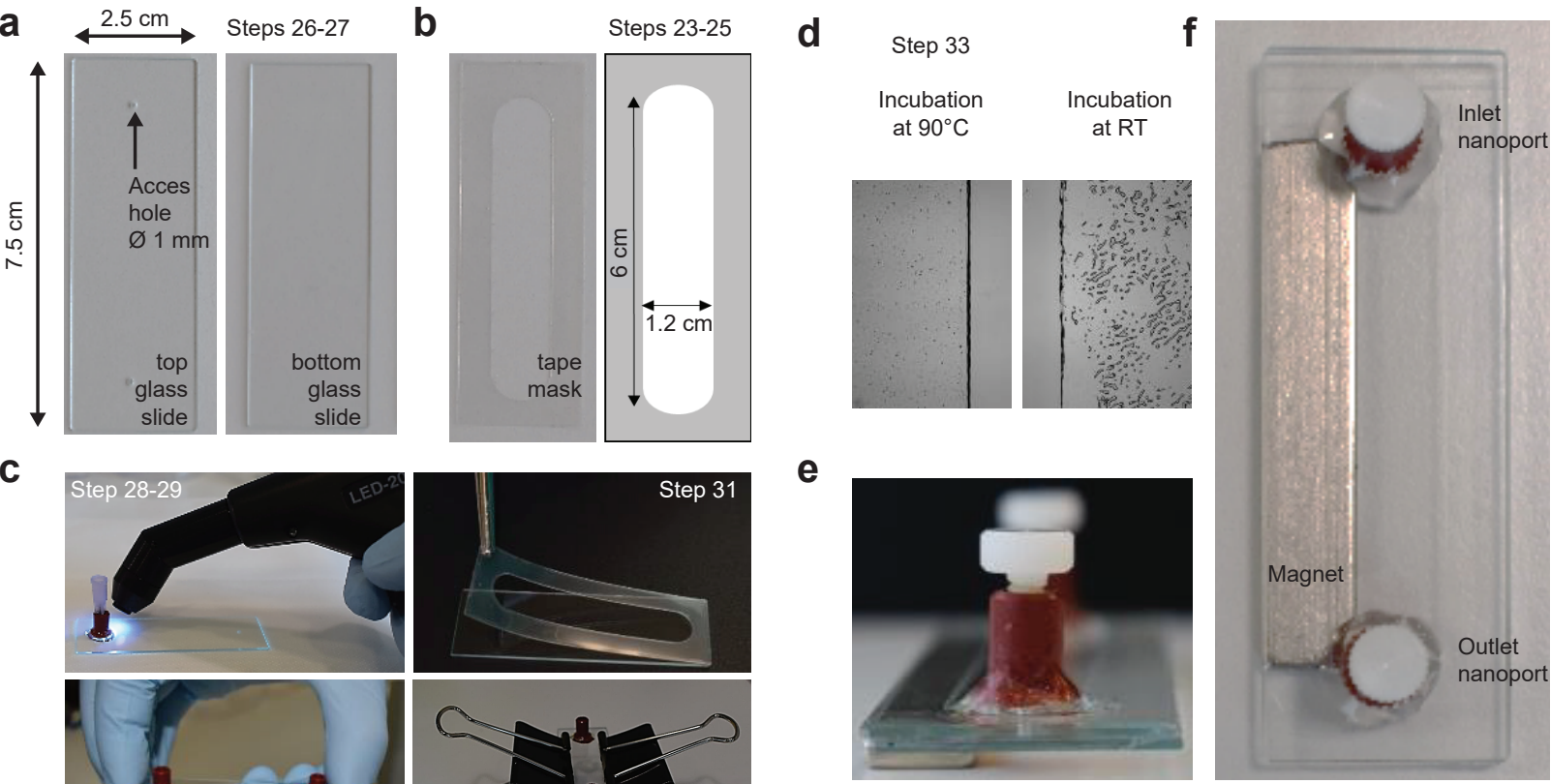

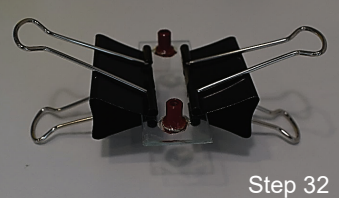

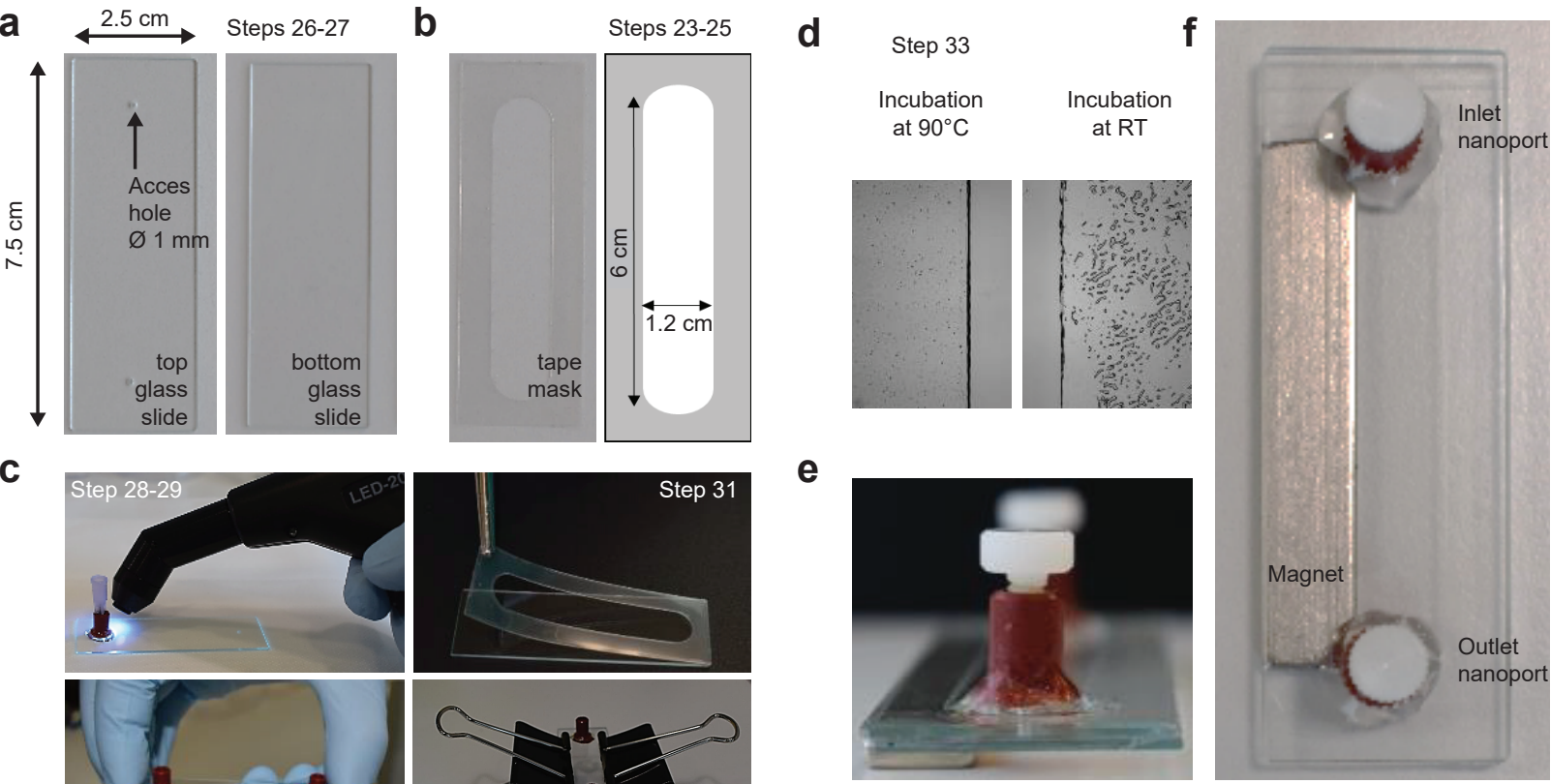

e

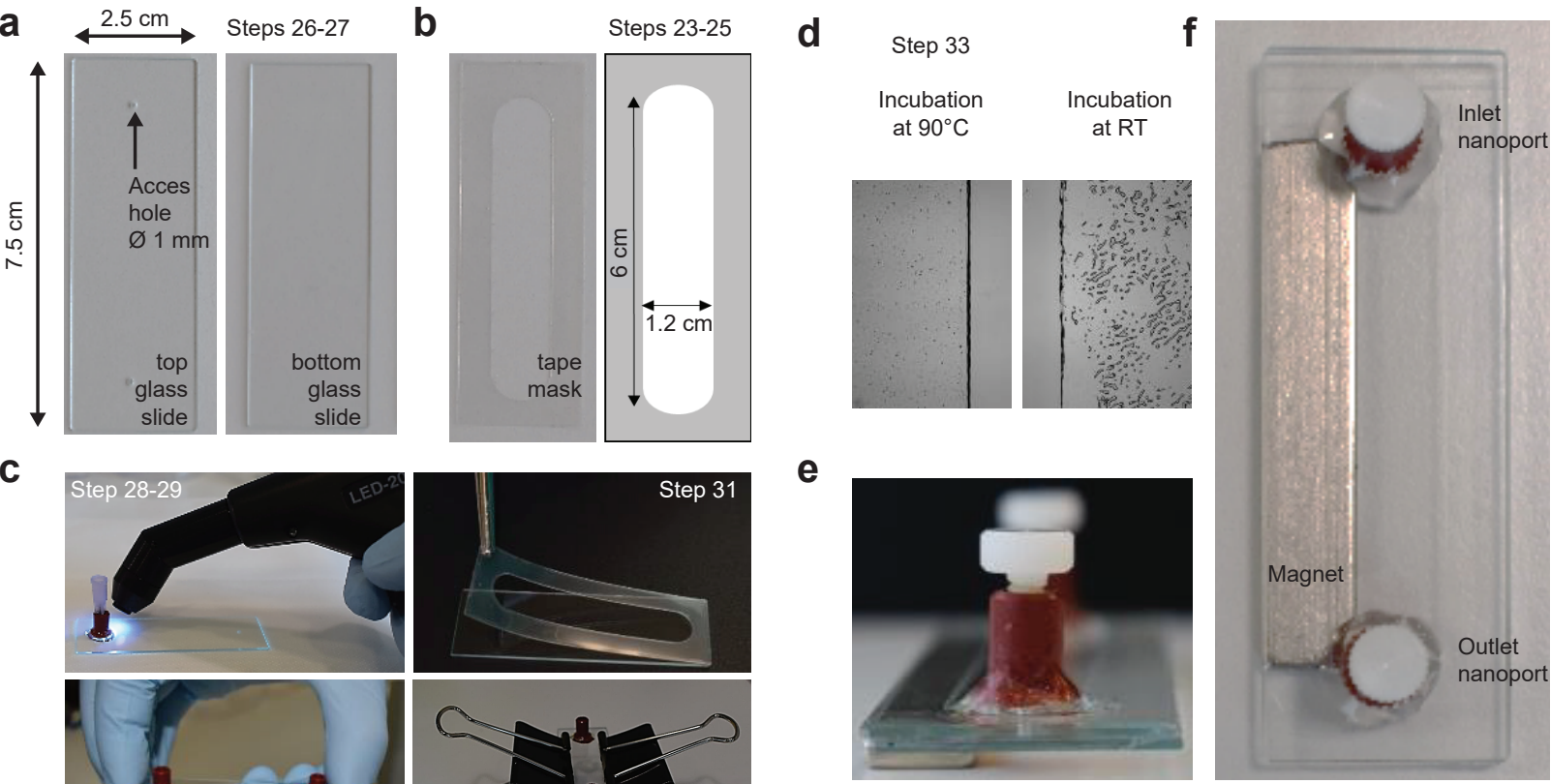

Inlet

nanoport

Outlet nanoport
Step 31

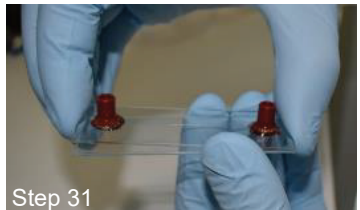

Step 32

Magnet

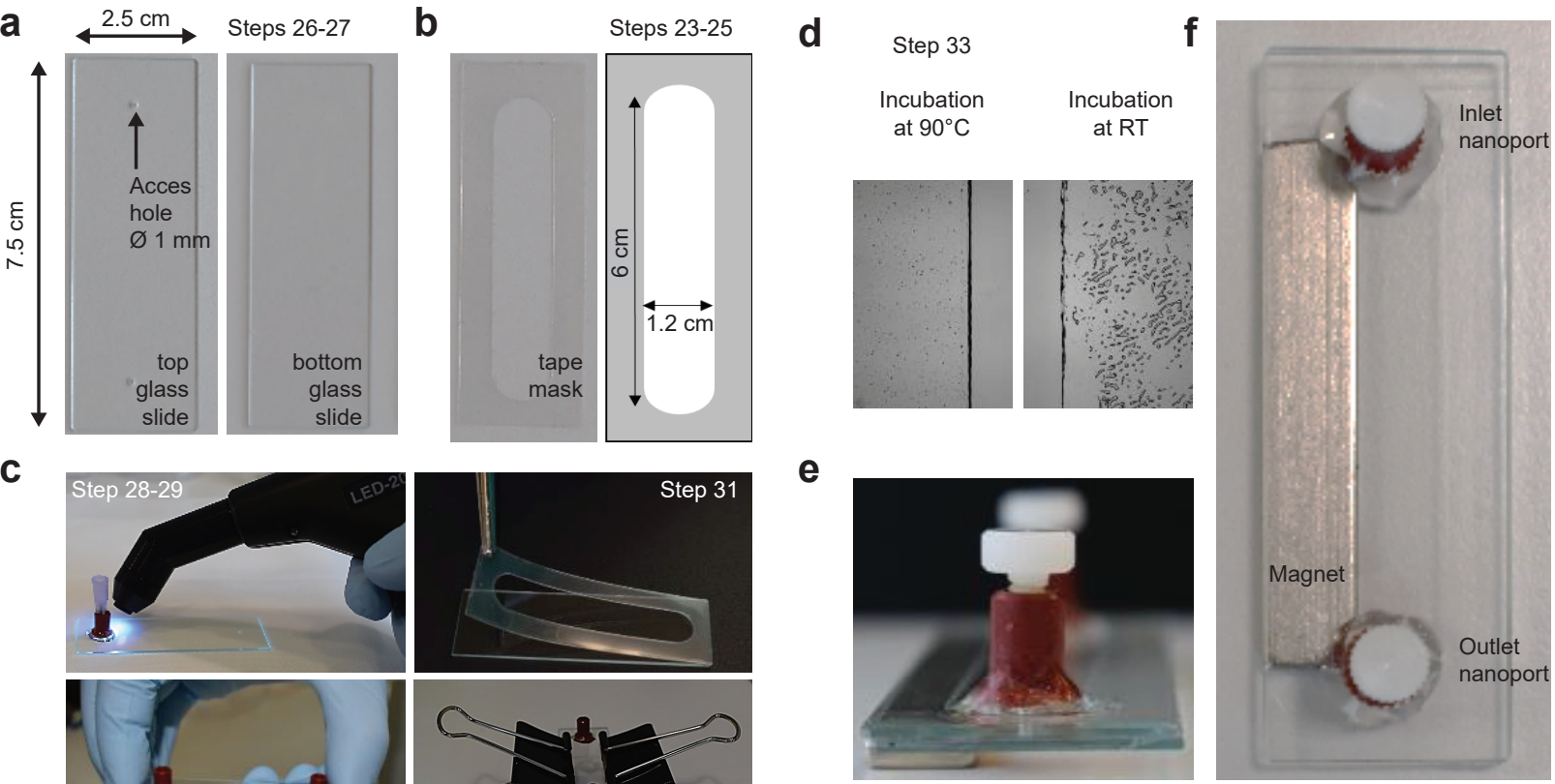


a $\quad$ Steps 47-102

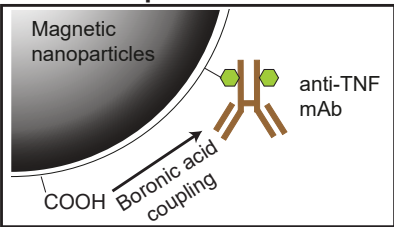

b
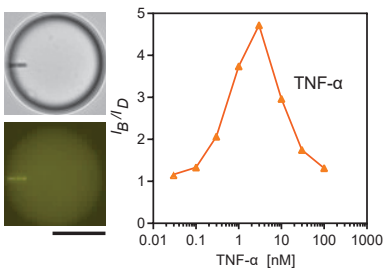

C
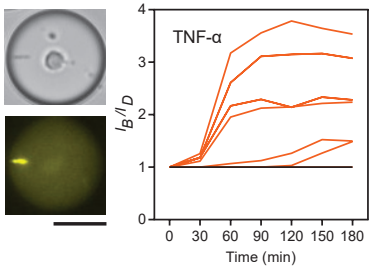

d

\section{Steps 103-111}

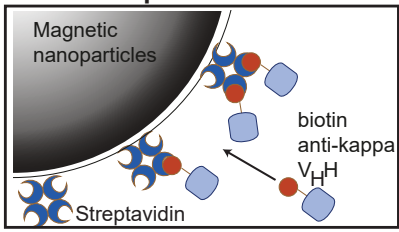

e
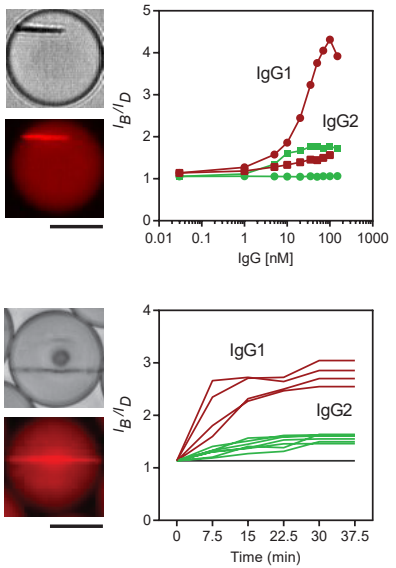

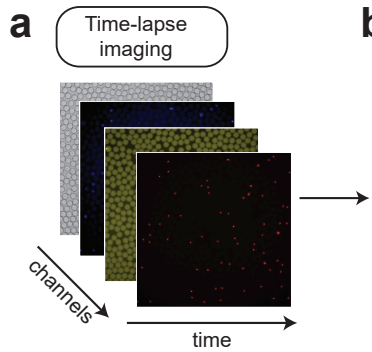

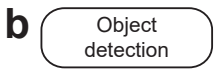

C

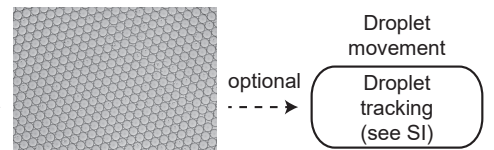

d

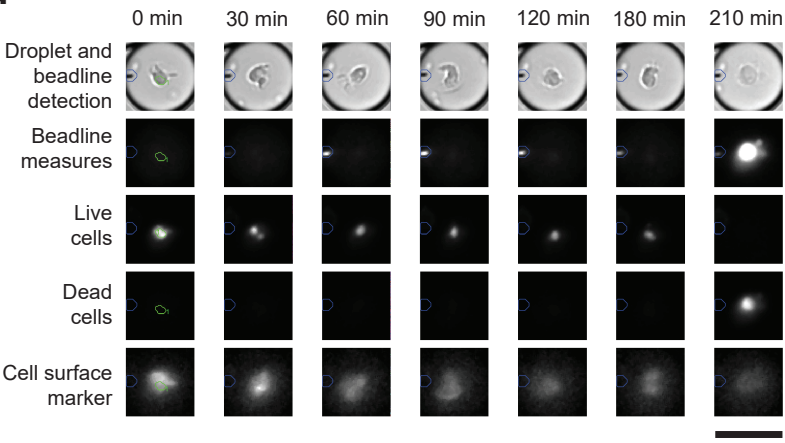

Filtering steps to select single-live cells

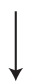




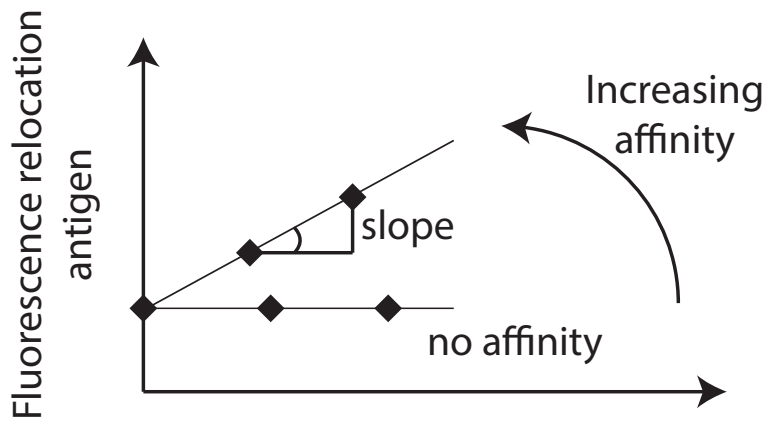

Fluorescence relocation anti-lgG

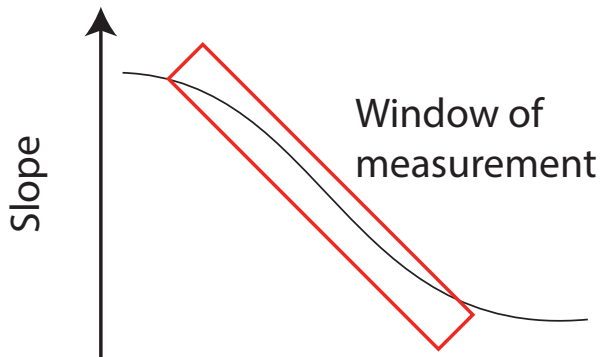

Affinity 